\title{
LA FORMACIÓN DE COMPAÑÍAS COMERCIALES EN SALAMANCA EN EL SIGLO XVI
}

\author{
Francisco Javier Lorenzo Pinar \\ Universidad de Salamanca
}

\begin{abstract}
Resumen. El presente artículo trata de reconstruir las condiciones bajo las cuales se fundaron las compañías comerciales en la urbe salmantina a lo largo del siglo XVI perfilando sus principales actividades, la duración de las mismas, los capitales invertidos, la categoría socio-profesional de sus integrantes y su radio de acción para establecer concomitancias o diferencias con otras sociedades mercantiles españolas. Supone una aportación a la historia de la práctica mercantil sobre una centuria y una zona escasamente abordadas.
\end{abstract}

Palabras clave: Compañías, comercio, mercaderes, Salamanca, siglo XVI.

Abstract. This paper tries to reconstitute the conditions for the foundation of the trading companies in the city of Salamanca (northwest of Spain). It studies the socio-professional category of the associates, their functions, their money contributions, the duration of the company and its geographical area of action. It'll also delineate the distinctive features or possible parallelisms with others Spanish societies and it'll try to verify some affirmations about the commercial activity of Salamanca during the Sixteenth Century. This article supposes a contribution to a subject scarcely studied for this century and for the interior places of the Iberian Peninsula.

Keywords: Trading societies, commerce, merchants, Salamanca, Spain, Sixteenth Century.

\section{Introducción}

A través de este artículo trataremos de aproximarnos a una temática que ha recibido una mayor atención para las ciudades costeras que para las interiores y que se ha

Recibido: 22/10/2012 - Aceptado: 23/07/2013 
centrado prioritariamente en los siglos XVII y XVIII ${ }^{1}$. Constituye una aportación para el conocimiento del comercio interno el cual ha suscitado un menor interés frente al colonial o a los grandes hombres de negocios ${ }^{2}$. El marco espacial donde se desarrolló la fundación de las compañías objeto de este estudio, la ciudad de Salamanca, contaba en 1561 con una población de 4.734 vecinos que disminuiría hasta los 4.109 en el año $1598^{3}$. Este potencial mercado, al que había que abastecer de productos básicos, junto a la presencia de uno de los principales centros universitarios, en el que llegaron a cursar durante algunos años más de 6.000 estudiantes, facilitó la creación de compañías mercantiles -en una cifra superior a las 78 a las que aluden las escrituras de fundación- dedicadas fundamentalmente a la comercialización textil, de ganado y de libros.

El establecimiento de contratos entre mercaderes, o entre estos y otros particulares para acciones comerciales conjuntas, aparece en el siglo XVI de una manera temprana en la urbe salmantina -el primer documento fundacional conservado es de 1511-; no obstante, la creación de sociedades mercantiles manifestará su máxima expansión durante las décadas de 1570 y 1580, período a partir del cual esta dinámica decae, diferenciándose en este sentido de la trayectoria seguida por la urbe zamorana donde los últimos años de la centuria manifestaron una intensidad idéntica a las dos décadas precedentes ${ }^{4}$. Los documentos utilizados, -ver tabla 3-, correspondientes al vaciado de la totalidad de los protocolos notariales relativos a este siglo, responden en su mayoría a fundaciones de compañías comerciales, las más abundantes de entre la totalidad de

Entre otros estudios véase PÉREZ SARRIÓN, G.: “Compañías mercantiles rurales y urbanas de Cataluña en el interior peninsular durante el siglo XVIII", en LOBO CABRERA, M. y SUÁREZ GRIMÓN, V. (Eds.), El comercio en el Antiguo Régimen. III Reunión Cientifica de la Asociación Española de Historia Moderna, Vol. II, Las Palmas de Gran Canaria, Universidad de las Palmas de Gran Canaria, 1994, p. 235.

2 Este fenómeno parece mucho más acentuado en países vecinos como Portugal. Algunos historiadores subrayan que la producción historiográfica sobre el comercio luso ha descuidado los niveles inferiores de intercambios y del comercio interno. FREIRE COSTA, L.: "Comércio e Familia em Portugal. Séculos XVI-XVIII" y SOLA-CORBACHO, J.C.: "Familia y comercio en España y Portugal (1500-1800), en SOARES DA CUNHA, M. y HERNÁNDEZ FRANCO, J. (Orgs.): Sociedade, familia e poder na Penísula Ibérica: elementos para uma histórica comparativa. LisboaMurcia, CIDEHUS-Universidad de Murcia, 2010, pp. 157 y 173 respectivamente; GONZÁLEZ ENCISO, A.: "El comercio en la España interior durante la época moderna", Obradoiro de Historia Moderna, 17, 2008, p. 21.

3 La población activa de la ciudad salmantina en la segunda mitad del siglo XVI, según datos de Francisco Javier Vela Santamaría, estaba aproximadamente en torno a un $10 \%$ dedicada al sector agrícola, un $49 \%$ al industrial, un $3 \%$ a la construcción y un $38 \%$ en los servicios. En el sector industrial los subsectores dominantes fueron el textil, el cuero y el calzado. VELA SANTAMARÍA, F.J.: "Salamanca en la época de Felipe II", en El pasado histórico de Castilla y León, V.2. Edad Moderna, Valladolid, Conserjería de la Junta de Castilla y León, 1984, pp. 286-287.

4 LORENZO PINAR, F.J.: "La formación de compañías comerciales en Zamora en el siglo XVI (1575-1600), Studia Historica. Historia Moderna, 35, 2013, pp.279-324. 
sociedades fundadas durante este período 5 . Hubo otras surgidas para el desarrollo de determinadas actividades laborales, caso de obras de carpintería; de bordado; de fabricación de campanas y esquilones; de naipes; para la extracción minera, o para el arrendamiento de rentas -de carácter financiero-, que no serán objeto de nuestro análisis ${ }^{6}$.

El recurso a la información obtenida a través de las escrituras fundacionales conservadas en los protocolos notariales de la ciudad de Salamanca plantea como primer problema la falta de series completas para la primera mitad del siglo. Además, nos queda la duda, a la hora de intentar delimitar el número de compañías que operaron, como sucedió para el estudio que realizamos sobre Zamora, de si cuando la documentación notarial alude a una determinada persona y "compañía" o "compañeros", hace referencia a una sociedad comercial o no7. Hemos también de tener en cuenta que algunas no dejaron, al menos inicialmente, escrituras fundacionales -sobre todo las de determinados libreros ${ }^{8}$ - o nunca las tuvieron, ya que no formalizaron su sociedad mediante documento público, circunstancia igualmente perceptible en otras zonas españolas a lo largo de toda la Edad Moderna9; que la documentación se ha podido

Las escrituras fundacionales constituyen una fuente clásica para este tipo de acercamientos temáticos cuya validez y riqueza informativa de cara al conocimiento de la vida económica han sido subrayadas por diferentes historiadores. Véase LE FLEM, J.P.: "La vision notariale du marchand á Ségovie (XVIe-XVIIe siécles)”, en PEREZ, B.; ROSE, S.V. y CLÉMENT, J-P. (Dirs.).: Des marchands entre deux mondes: pratiques et représentations en Espagne et en Amérique (XVeXVIIIe siècles), Paris, Presses de l’Université Paris-Sorbonne, 2007, p. 179.

Ágatha Ortega precisa que el hecho de que varios individuos aparezcan alguna vez compartiendo rentas no significa que hubiesen establecido compañías para tal efecto. ORTEGA CERA, Á.: "Estrategias, dinero y poder. Compañías financieras castellanas a finales de la Edad Media", en BONACHÍA HERNANDO, J.A. y CARVAJAL DE LA VEGA, D.: Los negocios del hombre. Comercio y rentas en Castilla. Siglos XV y XVI, Valladolid, Castilla Ediciones, 2012, p. 275.

7 Archivo Histórico Provincial de Salamanca (en adelante A.H.P.Sa). Protocolos Notariales (en adelante P.N.) Legajo (en adelante Leg.) 5077. 14-XI-1576. Fol. 364; Leg. 5078. 30-VII-1577. Fol. 319; Leg. 5079. 29-IX-1578. Fols. 183-185; Leg. 3666. 14-IX-1587. Fol. 582; Leg. 4076. 9-I-1588. Fols. 130-133; Leg. 4674. 29-XI-1596. Fols. 933-934.

8 Juan de Junta y Alejandro de Cánova decidieron en 1532 ratificar y continuar la compañía que habían mantenido durante una década bajo la siguiente declaración: “... por quanto della no ha havido ni hay escritura ninguna como no era razón y que no la hoviese donde tanta amistad y hermandad havía, mas de nuestras palabras; y agora, catando que somos mortales y que tenemos mugeres e hijos a quien, segund Dios y conçiençias somos obligados cada una a guardalle lo suyo y dexalles lo nuestro, sin que en ello haya pleito ni enbarazo, queremos hazer y hazemos la dicha compañía”. Los libreros Juan María de Terranova y Jacobo de Liarcari aparecen citados como compañeros en diferentes escrituras pero no se ha conservado el documento de fundación de la compañía. Lo mismo sucedió con la de los libreros Luis Méndez y Francisco de León; con la de Gaspar de Novela y Juan Moreno y su mujer Beatriz Rodríguez; o con la de Juan Fernández y Juan Boyer. A.H.P.Sa. P.N. 2924. 3-XI-1532. Fols. 33-36; Leg. 3650. 26-X-1550. Fols. 653-654 y 16XI-1550. Fol 692; Leg. 3651. 18-IX-1553. Fol. 466; Leg. 3657. 27-I-1570. Fols. 96-99; Leg. 4620. 3-VIII-1578. Fols. 1559-1561; Leg. 5269. 7-III-1597. Fols. 1062-1065.

9 Isabel Lobato subraya la importancia de los acuerdos verbales en el ámbito de la creación compañías por la no obligatoriedad de formalizarlas ante los escribanos. Por su parte Falah Hassan Abed Al- 
$\operatorname{perder}^{10}$, o que redactaron sus escrituras en otras urbes aunque establecieron su sede en Salamanca ${ }^{11}$. Como sucedió en otras ciudades algunas debieron funcionar sin contrato mercantil alguno basándose en la confianza mutua entre los socios ${ }^{12}$, aspecto que, junto a la reputación, ha sido contemplado como la base de la relación en el mundo de los negocios ${ }^{13}$. Las tratadas, por tanto, no constituyen sino una cifra aproximada sobre las realmente establecidas o que comercializaron en la ciudad. Debido a estas circunstancias la información de estas escrituras contractuales ha de ser necesariamente completada en un futuro con la ligada a las actividades realizadas por mercaderes que no pertenecieron a ningún tipo de compañías mercantiles, con la de los que desarrollaron su labor en el mundo de las finanzas e incluso con la de los profesionales del ámbito del transporte ya que si no obtendríamos una visión deformada de la realidad ${ }^{14}$. Así, por ejemplo, en la ciudad del Tormes no hemos hallado documentos fundacionales de ninguna compañía para comercializar con vino y sólo aparecen un par de ellas para negociar con pescado - producto este último con una notable presencia de sociedades comerciales en la ciudad vecina- ${ }^{15}$; sin embargo, sí encontramos referencias a comer-

Hussein señala que las sociedades medinenses formadas entre padres e hijos solían constituirse a menudo sin acuerdos escritos. LOBATO FRANCO, I.: "Reglamentación y práctica en las compañías mercantiles barcelonesas de la segunda mitad del siglo XVII", en MARTÍNEZ SHAW, C. (Ed.), El derecho y el mar en la España Moderna. Granada, Universidad de Granada, 1995, p. 63; AL-HUSSEIN, F. H.: "Las compañías o asociaciones de mercaderes", en LORENZO SANZ, E. (Coord.), Historia de Medina del Campo y su tierra. Auge de las ferias. Decadencia de Medina, Vol. II, Medina del Campo, Ayuntamiento de Medina del Campo, 1986, p. 195; FRANCH, R: Crecimiento comercial y enriquecimiento burgués en la Valencia del siglo XVI. Valencia, Institució Alfons el Magnànim 1986, p. 240.

Inés de Canillas en su contrato con su yerno Juan Rodríguez, mercader de ropas, alude a otra compañía que había mantenido anteriormente con su otro yerno Sebastián Valdenebro, de la cual carecemos de otras referencias. A.H.P.Sa. Leg. 2921. 5-VII-1527. Fols. 510-513.

11 A.H.P.Sa. P.N. 4620. 15-III-1578. Fols. 1486-1488.

12 Uno de los peligros que se corría en estos casos, como se observa en los litigios, era la negación de la existencia de la "sociedad", "compañía" o "trato" cuando se suscitaban diferencias en la liquidación de la misma. A(rchivo). de la R(eal).Ch(ancillería). de Va(lladolid). Registro de Ejecutorias. Caja 1437, 59. Ejecutoria del pleito litigado por Miguel de Alcántara, vecino de Argujillo (Zamora), con Gonzalo Hernández, vecino de Ledesma (Salamanca). 10-III-1581.

13 ANGULO MORALES, A.: "Los dilemas de la burguesía y el comercio vascos en la España Moderna. Un estado de la cuestión”, en ARANDA PÉREZ, F.J., Burgueses o ciudadanos en la España Moderna, Cuenca, Ediciones de la Universidad de Castilla-La Mancha, 2003, pp. 319320; BALARD, M.: "La culture du marchand occidental en Méditerranée orientale", en AURELL, J. (Ed.), El Mediterráneo medieval y renacentista, espacio de mercados y de culturas, Pamplona, Ediciones Universidad de Navarra, 2002, p. 42.

14 LORENZO PINAR, F.J. e IZQUIERDO MISIEGO, J.I.: “El transporte universitario concertado salmantino en el siglo XVI", Miscelánea Alfonso IX, 2011, pp. 345-372.

15 A.H.P.Sa. Leg. 4874. 11-IV-1596. Fols. 941-942; A.R.Ch.Va. Registro de Ejecutorias. Caja 1396, 24. Ejecutoria del pleito litigado entre los herederos de María García y Francisca Rodríguez. 16-IX1579. 
ciantes que adquirieron pescado - sardina y sábalo- de Galicia o de Portugal de manera individualizada o en grupo sin tener constancia de que formalizasen compañías ${ }^{16}$. También hay que tener en cuenta para poder calibrar la importancia que tuvo el consumo de estos géneros, la existencia en la urbe de la red del pescado fresco y de bodegas en los arrabales donde se podía vender este producto cocido o asado para comerlo en el establecimiento; o la presencia de la tabernilla y la alhóndiga del vino que el Ayuntamiento, junto a la citada red, solía poner en renta, dato indicativo de la extensión del consumo de este producto y de su rentabilidad ${ }^{17}$. El vino constituyó, por otro lado, una de las mercancías sobre la cual se prescribieron un elevado número de ordenanzas en la legislación local salmantina y se le ha considerado en los estudios locales como uno de los productos de consumo masivo ${ }^{18}$. Las ordenanzas prohibían que los vecinos de la ciudad tuviesen compañía para su venta, directa o indirectamente, con personas que lo trajeran desde fuera ${ }^{19}$. La naturaleza de los documentos empleados no nos permite tampoco establecer tendencias de consumo o hábitos de lectura, tal y como han efectuado otros trabajos a través de memoriales, inventarios o libros de contabilidad que no se conservan en el caso salmantino ${ }^{20}$.

Otra de las dificultades con las que nos encontramos al aproximarnos al tema reside en delimitar el carácter de estas vinculaciones contractuales. Salvo en dos casos relacionados con el comercio de ganado, el resto de las escrituras denominaron estas fundaciones como compañías. Lo hicieron bajo los títulos de "carta", "escritura", "contrato" u "obligación de compañía"; "carta de sociedad e compañía"; "pública escriptura de conpañía, trato e concordia a pérdida y ganançia"; "carta de amistad y compañía"; "pública escritura de concierto y compañía"; "carta de asiento y compañía" o

A.H.P.Sa. P.N. Leg. 3143. 4-VIII-1539. Fols. 106-107; Leg. 5088. 13-VII-1599. Fol. 59.

LlOPIS, S.: Ensayo sobre la historia del comercio Salamantino, Salamanca, Gráficas Cervantes, 1965, pp. 20, 23, 76 y 217; LARRUGA, E.: Memorias politicas y económicas sobre los frutos, comercio, fábricas y minas de España, Vol. XXIV, [Ed. Facsímil, Zaragoza, Gobierno de Aragón, 1996], p. 202.

18 Había que abastecer de este producto a una ciudad que según Javier Infante contaba hacia 1517 con unos 20.000 habitantes. INFANTE MIGUEL-MOTTA, J.: El municipio de Salamanca a finales del Antiguo Régimen. Contribución al estudio de su organización institucional, Salamanca, Ayuntamiento de Salamanca, 1984, p. 23.

$19 \quad$ Ibídem, pp. 220-224; MARTín J. L.: Ordenanzas del comercio y de los artesanos salmantinos. Salamanca, Centro de Estudios Salmantinos, 1992, p. 12; VACA LORENZO, Á. y RUPÉREZ ALmajanO, $\mathrm{M}^{\mathrm{a}}$. N.: La Plaza Mayor de Salamanca. I. Antecedentes medievales y modernos, Salamanca, Caja Duero, 2005, p. 86.

$20 \quad$ Entre los estudios de este estilo se deben resaltar los de B. Blondé para Holanda o Evelyn Welch para algunas ciudades italianas. BLONDÉ, B. y VAN DAMME, I.: "Fashioning Old and New or Moulding the Material culture of Europe (Late Seventeenth-Early Nineteenth Centuries)", en BLONDÉ, B., COQUERY, N. STOBART, J. y VAN DAMME, I.: Fashioning Old and New. Changing Consumer Patterns in Western Europe (1650-1900), Belgium, Brepols, 2009, pp. 1-13; WELCH, E.: De compras en el Renacimiento, Valencia, Universidad de Valencia, 2009. 
“compañía y hermandad". A pesar de ello, en la mitad de los casos estas corporaciones mercantiles presentaron las características propias de lo que los historiadores han calificado como comendas mercantiles al responder a un contrato por el cual el comandante entregaba un capital en metálico o las mercancías para que el comendatario negociase, aunque en el caso salmantino nunca estuvo ligado este acto jurídico a un viaje marítimo como en otras zonas españolas; de ahí las dudas a la hora de conceptualizarlas ${ }^{21}$.

\section{La masa social}

La masa social de las compañías, como fue habitual en otras partes, manifiesta un claro predominio de varones entre los socios - cuatro de cada cinco- aunque las mujeres estuvieron presentes en cuatro de cada diez compañías, cifra elevada pero tal vez distorsionada por la presencia de una misma fémina en varias de ellas. Fue el caso de Susana Hernández, viuda de un sastre, quien actuó como socia capitalista en diez de las sociedades destinadas al trato de ganado. Al igual que en otras zonas castellanas encontramos compañías limitadas en cuanto al número de sus socios, reducidos a dos o a tres sin que se supere esta cifra salvo la de libreros establecida en la década de 1530 -ver tabla 1_22. A lo largo de todo el siglo, salvo en la segunda década, se observa un claro predominio de las formadas por dos socios - tres cuartas partes de las mismas-. El incremento del número de socios hasta tres, perceptible sobre todo en las compañías establecidas entre 1570 y 1590, período de mayor número de fundaciones, responde a la formación de compañías de carácter familiar en las que se da cabida al cónyuge, los hijos o los hermanos.

La mayoría de los componentes de estas compañías procedía de la urbe o de los pueblos salmantinos, observándose una reducida presencia de foráneos residentes en Trujillo, Valladolid, Medina del Campo, o que habían llegado a la ciudad desde diferentes lugares de Europa -Italia, Francia y Flandes, principalmente-. Estos últimos estuvieron ligados sobre todo al mercado del libro. La participación de familiares -matrimonios y hermanos fundamentalmente- estuvo presente en algo más de

$21 \quad$ MARTÍNEZ GIJÓN, J.: "La comenda en el Derecho Español. II. La comenda mercantil”, Anuario de Historia del Derecho Español, T. XXXVI, 1966, pp. 379-476; LOBO CABRERA, M.: El comercio canario europeo bajo Felipe II, Las Palmas de Gran Canaria, Viceconserjería de Cultura y Deportes,1988, p. 83.; GRENIER, J-Y.: L'économie D'Ancien Régime: un monde de l'échange et de l'incertitude, París, Albin Michel Litterature, p. 93 ; IMBERT, J. : "Evolutión du régime juridique de l'enterprise", en CAVACIOCCHI, S. (a cura di) : L'impresa : industria, commercio, banca, secc. XIII-XVIII : atti della «ventiduesima Settimana di Estudi», Firenze, Le Monnier, 1991, p. 65; PETIT, C.: La compañia mercantil bajo el régimen de las ordenanzas del Consulado de Bilbao. 1737-1829, Sevilla, Universidad de Sevilla, 1980, p. 50.

22 Una tendencia similar a la observada en Tierra de Campos. Véase YUN CASALILLA, B.: Sobre la transición al capitalismo en Castilla. Economía y sociedad en Tierra de Campos (1500-1800), Valladolid, Junta de Castilla y León, 1987, p. 198. 


\begin{tabular}{l} 
Tabla 1. Número de socios que integran las compañías comerciales salmantinas. Siglo XVI. \\
Fuente: Escrituras de fundación. Protocolos. A.H.P.Sa. \\
\hline $\begin{array}{c}\text { No de } \\
\text { socios }\end{array}$ \\
\hline
\end{tabular}

una quinta parte de las compañías ${ }^{23}$. Se trata de un porcentaje que triplica la proporción de ciudades vecinas como Zamora y en la línea de las andaluzas en el comercio canario americano donde predominaron las constituidas por mercaderes sin mediar entre ellos ningún lazo de parentesco ${ }^{24}$. Este comportamiento fue diferente al de otras ciudades castellanas durante finales de la Baja Edad Media, caso de Burgos o Segovia $^{25}$; o al de otras zonas españolas para el siglo XVI - caso de Canarias-26 ${ }^{26}$ e incluso al de comerciantes extranjeros, como los portugueses, donde los vínculos de sangre y de confianza personal entre los asociados jugaron un papel más relevante tanto en esta centuria como en la siguiente ${ }^{27}$. Como sucedió en otras ciudades españolas y

23 Diferentes estudios han subrayado el relevante peso de la familia en las compañías comerciales a lo largo de la Edad Moderna. Véase GÓMEZ CARRASCO, C. J.: Familia y capital comercial en la Castilla meridional: la comunidad mercantil en Albacete (1700-1835), Madrid, Sílex Ediciones, 2009, pp. 98 y 101; RODRÍGUEZ DE GRACIA, H.: "Mercaderes y asociaciones mercantiles en el comercio toledano de la seda en la segunda mitad del siglo XVII", Hispania, 210, 2002, pp. 65112; MELÓN JIMÉNEZ, MIGUEL ÁNGUEL: Los orígenes del capital comercial y financiero en Extremadura. Compañias de comercio y banqueros de Cáceres (1773-1836), Badajoz, Diputación Provincial de Badajoz, 1996, p. 97; BUSTOS RODRÍGUEZ, M.: Cádiz en el sistema atlántico. La ciudad, sus comerciantes y la actividad mercantil (1650-1830), Cádiz, Universidad de Cádiz, 2005, p. 469; FRANCH, R.: Op. cit., p. 243.

24 Esta tendencia se observa en Cataluña para el siglo XVII donde sólo 20 de las 151 compañías reseñadas estuvieron formadas por miembros de una misma familia. LOBO CABRERA, M.: "Compañías andaluzas en el comercio canario americano", Historia, Instituciones y Documentos, 20, 1993, p. 198; LOBATO FRANCO, I.: Compañias y negocios en la Cataluña Preindustrial, Sevilla, Universidad de Sevilla, 1995, p. 42.

25 CAUNEDO DEL POTRO, B.: "Compañías mercantiles castellanas a fines de la Edad Media", Medievalismo, 3, 1993, p. 40; ASENJO GONZÁLEZ, M.: "Participación de las mujeres en las compañías comerciales castellanas a fines de la Edad Media. Los mercaderes segovianos", en MUÑOZ FERNÁNDEZ, A. y SEGURA GRAÍÑO, C., El trabajo de las mujeres en la Edad Media Hispana, Madrid, Asociación Cultural Al-Mudayna, 1988, p. 225; VALDEÓN BARUQUE, J.: "El comercio y las instituciones mercantiles en la Castilla del siglo XV”, en SUÁREZ FERNÁNDEZ, L. y GUTIÉRREZ NIETO, J. I. (Coords.), Las instituciones castellano-leonesas y portuguesas antes del Tratado de Tordesillas, Valladolid, Sociedad V Centenario del Tratado de Tordesillas, 1995, p. 173. LOBO CABRERA, M.: El comercio canario...op. cit., p. 85.

27 CARRASCO, R.: "Négoce et pouvoir municipal: les marchands de Cuenca à la époque de Philippe II", en PEREZ, B.; ROSE, S.V. y CLÉMENT, J-P. (Dirs.)., Des marchands entre deux mondes: pratiques et représentations en Espagne et en Amérique (Xve-XVIIIe siècles), Paris, Presses de l'Université Paris-Sorbonne, 2007, p. 170 ; BROENS, N. : Monarquía y capital mercantil: Felipe IV y las redes comerciales portuguesas (1627-1635), Madrid, Universidad Autónoma de Madrid, 1989, p. 41. 
extranjeras la participación en las compañías no estuvo limitada exclusivamente a mercaderes observándose en las salmantinas la presencia de artesanos, del clero y de individuos de profesiones liberales (licenciados, procuradores y médicos) que buscaban incrementar su fortuna valiéndose de la pericia de los hombres de negocios ${ }^{28}$.

\section{Las normas de articulación interna}

Los documentos notariales que materializaron la fundación de estas compañías, aconsejables, como ha señalado José Martínez Gijón, para "garantizar los derechos de los terceros contratantes o para resolver las disensiones que pudieran surgir", establecieron cláusulas contractuales fundamentalmente relacionadas con el tipo de actividad que iba a desarrollar cada uno de los socios, los aportes de capital social, la duración de la sociedad o el margen de beneficios y pérdidas, centrándose en escasa medida en lo relativo a aspectos como la administración, los supuestos de enfermedad o muerte de los asociados, o las eventualidades que podían conducir a disolver$\operatorname{las}^{29}$. En su redacción emplearon todavía algunas expresiones que podían considerarse como propias de la Edad Media, caso de las invocaciones explícitas de carácter religioso y contenido trinitario ("en el nonbre de Dios, Nuestro Señor Ihesú Cristo, Padre e Hijo e Espíritu Santo, que son tres personas en un solo Dios verdadero e de la Santísima Trinidad) o del estilo: "mediante la boluntad de Nuestro Señor e a su santo serviçio"; "con el fabor e ayuda de Nuestro Señor Jesuchristo e de la gloriosa Virgen María, Nuestra Señora, su bendita madre, a quien tomamos y escojemos por nuestra abogada e interçesora, para que sea en rogar a nuestro Señor Jesuchristo nos quiera favorecer e ayudar en lo que posiéremos mano, amén"; "a servicio de Dios Nuestro Señor y alabanza de su gloriosa madre y gloria de todos los santos, mayormente de señor san Marcos y señor san Roque, cuyos naturales y debotos somos"; "la ganancia que Dios diere" o "donde Dios les guiare"30. También resulta frecuente la referencia, al inicio o a la finalización de los contratos o en el establecimiento de cuentas, a una

28 Subrayan la participación de un amplio espectro social en las compañías estudios como los de MARTIN, R.: “Trade and traders: Endinburgh's sixteenth-century exporting community". Historical Research, 81, 2008, p. 449.

29 MARTÍNEZ GIJÓN, J.: La compañia mercantil en Castilla hasta las Ordenanzas del Consulado de Bilbao de 1737. Legislación y doctrina, Sevilla, Universidad de Sevilla, 1979, p. 83.

$30 \quad$ Así ha interpretado M. Basas estos rasgos que se hallan también en las letras de cambio de este siglo. Véase BASAS FERNÁNDEZ, M.: "Contratos de compañías mercantiles castellanas del siglo XVI”, Revista de Derecho Mercantil, 30, 1960, p. 380. A.H.P.Sa. P.N. Leg. 2924. 3-XI-1532; Fols. 33-36. Leg. 2929. 5-XI-1548. Fols. 227-230; Leg. 2946. 6-IV-1571. Fols. 539-543; Leg. 3650. 7-II1550. Fols. 104-105; Leg. 3370. 21-I-1551. Fols. 423-424; Leg. 3363. 15-IX-1531. Fols. 423-424 y Leg. 5306. 19-XII-1578. Fols. 1065-1067. 
fecha religiosa o al santo de ese día -Pascua de Flores, San Miguel, San Martín, Navidad, San Juan, Nuestra Señora de septiembre, etc.-.

Uno de los aspectos que habitualmente conforma las cláusulas fundacionales de las compañías radica en la determinación de su capital social, especialmente lo referido a la parte monetaria dado que, salvo en los roperos y libreros, resultaron extrañas las aportaciones en géneros o créditos. En seis de cada diez compañías al menos uno de los socios proporcionó exclusivamente su trabajo personal, especialmente en las dedicadas al trato de ganado o en las que no indicaron su objeto social ${ }^{31}$. El capital en efectivo, como se aprecia también en la ciudad vecina de Zamora, varió ostensiblemente de unas a otras, desde los 100 a los casi 95.000 reales -ver tabla 3-, siendo las sociedades destinadas al ámbito editorial las que mayor volumen de inversión requirieron. En algunos casos se trata de cifras aproximadas ya que una de cada ocho ni siquiera lo indicó. De manera minoritaria el capital social estuvo ligado a muebles, ropas, deudas o letras ${ }^{32}$. En algunas compañías se especificó que no formasen parte de tal concepto los bienes muebles, raíces, joyas o el dinero que las mujeres de los mercaderes hubiesen llevado al matrimonio, probablemente porque se trataba de un capital problemático en el caso de fallecimiento del socio ya que la viuda estaría dispuesta a reclamarlo a los compañeros ${ }^{33}$. En ocasiones encontramos un amplio margen de confianza entre los socios cuando se establecía la sociedad al señalarse que estos fuesen creídos "por lo que dixeren" a la hora de aportar mercancías ${ }^{34}$. No obstante, tampoco debemos magnificar este aspecto. Los pleitos conservados en la Real Chancillería de Valladolid ponen de relieve que no siempre las relaciones discurrieron en el ámbito de la cordialidad. Se constatan sospechas de uno de los socios hacia el otro por su enriquecimiento ostentoso, perceptible en la adquisición de numerosas propiedades, teóricamente con el capital de la compañía; se requirieron fianzas ante posibles dictámenes judiciales o se procedió al rechazo de jueces compromisarios que no eran del agrado de una de las partes ${ }^{35}$.

31 Se trata de un porcentaje elevado si lo comparamos con ciudades como Zamora para la misma época, donde no llegó a una de cada cinco, o el de otras urbes para épocas posteriores, como Cádiz (un 11,5 por ciento de las compañías). CARRASCO GONZÁLEZ, M. G.: Comerciantes y casas de negocios en Cádiz (1650-1700), Cádiz, Universidad de Cádiz, 1997, p. 60.

32 Bárbola Hernández aportó 2.873 reales en deudas para el trato de ropería con su hijo Juan. Lucas de Mora ingresó en la compañía 5.800 reales en paños y deudas, y su hermano 75.000 maravedíes en dineros y paños. A.H.P.Sa. P.N. Leg. 3487. 29-V-1599. Fols. 762-764; Leg. 5250. 9-VI-1576. Fols. 1118-1119.

33 A.H.P.Sa. P.N. Leg. 2924. 3-XI-1532. Fols. 33-36.

34 A.H.P.Sa. P.N. Leg. 5248. 21-IX-1574. Compañía entre Juan González y Francisco de Almaraz, mercaderes. S.f.

35 A.R.Ch.V. Registro de Ejecutorias. Caja 304-23. Ejecutoria del pleito litigado por Alonso Gutiérrez con Hernando de Manzanedo, mercader, vecinos de Ciudad Rodrigo (Salamanca). 28-IX-1515. 
Una de las preocupaciones principales de los socios radicó en establecer el margen de beneficios o pérdidas que iba a corresponder a cada uno de los compañeros. En las compañías salmantinas predominó un reparto igualitario denominado en las fuentes como "a pérdida e ganancia", aunque no siempre los socios contribuyesen con el mismo capital en efectivo ${ }^{36}$. Así sucedió habitualmente en los casos en los que un socio aportaba capital monetario y el otro $u$ otros se dedicaban a realizar el trabajo -labores administrativas, de adquisición de género, etc.- de las cuales estaba excluido el socio capitalista. En otras ocasiones se empleó este sistema aunque ambos socios participasen en la comercializaron del género e introdujesen diferentes capitales, debido fundamentalmente a razones de familiaridad entre ellos ${ }^{37}$. A pesar de este predominio de la tendencia de reparto paritario nos encontramos con situaciones diversas que desequilibraban la balanza hacia uno u otro socio en función de su preparación o de la labor desarrollada. Así por ejemplo, en la sociedad entre Alonso García, sastre, y el calcetero Antonio del Castillo, al no estar aquél "bien astuto en el oficio de calcetería de la manera que Antonio" tuvo que poner un oficial a su costa hasta hallarse preparado para que ninguna de las partes "recibiese menoscabo". En este caso los beneficios y pérdidas no se repartirían igualmente entre los socios ${ }^{38}$. En la de Cristóbal Cortés y Juan García, mercaderes de paños, este último habitaría solo en la casa de la compañía y recibiría un salario anual de 24.000 maravedíes, probablemente por su mayor ocupación en el negocio ${ }^{39}$. En otras ocasiones el socio capitalista no se responsabilizaba si la operación de compra o de venta resultaba "ynçierta", con lo cual su riesgo de pérdida resultaba menor ${ }^{40}$. También hallamos supuestos en los que si uno de los compañeros enfermaba el otro trataría "la mercancía como para sí mismo" durante el período de la convalecencia, lo cual suponía un incremento en sus beneficios ${ }^{41}$. De cualquier modo, todas estas situaciones constituyeron una minoría frente a la tendencia general.

Si atendemos al ciclo vital de estas sociedades -ver tabla 2-, la cifra moda se sitúa en las fundadas para operar entre uno y dos años; casi la mitad del total carecieron de mayor duración. Mantienen en este sentido una vida activa menor que las de otras zonas, caso de la aragonesa, donde casi la mitad operaron en períodos entre

\footnotetext{
36 A.H.P.Sa. P.N. Leg. 2912. 5-VIII-1516. Fols. 1081-1084.

37 Antonio Vicente, mercader de ropas, procedía a un reparto igualitario con su hijo Francisco bajo la siguiente consideración: "atento que somos padre e hijo". A.H.P.Sa. P.N. Leg. 5458. 31-I-1586. Fols. 199-200.

38 A.H.P.Sa. P.N. Leg. 2925. 5-IX-1533. Fols. 280-281.

39 A.H.P.Sa. P.N. Leg. 3650. 7-II-1550. Fols. 104-105.

40 A.H.P.Sa. P.N. Leg. 4612. 26-IV-1572. Fol. 1742.

41 A.H.P.Sa. P.N. Leg. 5248. 21-IX-1574. S.f.
} 


\begin{tabular}{|c|c|c|c|c|c|c|c|c|c|c|}
\hline \multicolumn{11}{|c|}{$\begin{array}{l}\text { Tabla 2. Vigencia de las compañías de la ciudad de Salamanca. Siglo XVI. } \\
\text { Fuente: Escrituras de fundación. Protocolos Notariales del A.H.P.Sa. }\end{array}$} \\
\hline \multirow[t]{2}{*}{ Duración } & \multicolumn{10}{|c|}{ Número de Compañías } \\
\hline & $\begin{array}{l}1501- \\
1510\end{array}$ & $\begin{array}{l}1511- \\
1520\end{array}$ & $\begin{array}{l}1521- \\
1530\end{array}$ & $\begin{array}{l}1531- \\
1540\end{array}$ & $\begin{array}{l}1541- \\
1550\end{array}$ & $\begin{array}{l}1551- \\
1560\end{array}$ & $\begin{array}{l}1561- \\
1570\end{array}$ & $\begin{array}{l}1571- \\
1580\end{array}$ & $\begin{array}{l}1581- \\
1590\end{array}$ & $\begin{array}{l}1591 \\
1600\end{array}$ \\
\hline Menos de un año & Sin datos & 1 & 0 & 0 & 2 & 0 & 2 & 4 & 6 & 2 \\
\hline De 12 a 23 meses & Sin datos & 0 & 0 & 2 & 1 & 1 & 0 & 3 & 11 & 1 \\
\hline De 24 a 35 meses & Sin datos & 3 & 0 & 1 & 0 & 1 & 0 & 1 & 2 & 0 \\
\hline De 36 a 48 meses & Sin datos & 0 & 0 & 0 & 1 & 0 & 0 & 3 & 1 & 0 \\
\hline Más de 4 años & Sin datos & 0 & 3 & 1 & 2 & 0 & 1 & 3 & 0 & 0 \\
\hline Sin deter-minar & 0 & 0 & 0 & 2 & 0 & 0 & 1 & 6 & 6 & 4 \\
\hline
\end{tabular}

cuatro y seis años ${ }^{42}$. Esta circunstancia nos habla de una proyección a corto plazo de las sociedades salmantinas, las cuales intentarían obtener unos beneficios rápidos sin que necesariamente los volviesen a invertir, afirmación que sostenemos puesto que no se repiten los nombres de los mercaderes que fundaron compañías a lo largo del tiempo. También llama la atención la elevada cifra de sociedades que no determinaron la vigencia de sus vinculaciones, especialmente en las tres últimas décadas del siglo; tal vez porque sus socios deseaban comprobar la marcha del negocio y verse libres para disolver la sociedad en cualquier momento si no resultaba rentable. De este modo procedió Melchor Martínez, clérigo, quien acordó a la hora de establecer su compañía que siempre que desease sacar su dinero lo podría hacer estando obligado "a pasar" por las cuentas que ofreciese su socio ${ }^{43}$. Entre las de mayor duración destacan algunas en las que los compañeros compartían lazos familiares, caso de la de Lucía Martín, viuda, y su hija Isabel Sánchez, vecinas de Salamanca, para el trato de frutas y telas que confirieron a su sociedad un carácter vitalicio ${ }^{44}$.

Los temas relacionados con la administración de la compañía, como ya indicábamos, apenas son objeto de atención de los contratos fundacionales; de hecho, sólo en un 5 por ciento de éstos señalan de manera explícita en quién debía recaer la gestión, la cual no se vinculó necesariamente a la persona que aportaba el mayor capital monetario. Se trata fundamentalmente de una administración única pero no ligada a individuos cuya función estuviese reducida exclusivamente a aspectos financieros o contables $^{45}$. Para poder llevar a cabo la contabilidad probablemente en algunos casos se vieron obligados a recurrir a individuos ajenos a la compañía ya que en al menos

42 GÓMEZ ZORRAQUINO, J.I.: La burguesía mercantil en el Aragón de los siglos XVI y XVII (1516-1652), Zaragoza, Diputación General de Aragón, 1987, p. 120.

43 A.H.P.Sa. P.N. Leg. 3876. 7-IV-1575. Fols. 34-35.

$44 \quad$ A.H.P.Sa. P.N. Leg. 2916. 31-XII-1522. Fol. 121.

45 Esta tendencia se observa en otras zonas como Cataluña aunque para el siglo XVII. LOBATO FRANCO, I.: "Modelos y métodos de gestión en la compañía preindustrial (Barcelona, 16501720), Cuadernos de Estudios Empresariales, 30, 1996, p. 232. 
un 18 por ciento de los casos ninguno de los socios supo firmar las escrituras; o tal vez no siempre contaron con documentos contables ${ }^{46}$.

La rendición de cuentas podía realizarse durante o después de la vida de la compañía. Había quienes preferían un control sistemático de los resultados fijando revisiones de las mismas de manera trimestral, cuatrimestral, anual o cada vez que lo solicitase el socio capitalista ${ }^{47}$. La de Diego Palomeque y el carpintero Cristóbal Sánchez, fundada para tratar con madera, realizaría el "abanco" cada tres meses y cada vez que realizasen balance si deseaban sacar el capital monetario invertido lo podían hacer $^{48}$. El joyero Benito de Saucelle, quien había recibido 100 ducados del médico Antonio de Parra para la compra de sedas en Toledo, estaba obligado a dar cuentas cada cuatro meses y una vez pasados los ocho primeros, Antonio podría demandarle el capital invertido cuando lo desease ${ }^{49}$.

El balance se llevaba a cabo considerando no sólo lo anotado en los libros de cuentas sino también en otras escrituras -obligaciones, conocimientos, letras, etc.e incluso se le confería validez a las declaraciones de los testigos presentes en las transacciones ${ }^{50}$. Uno de los problemas que debían afrontar los socios era el cobro de las deudas pendientes. En ocasiones se daba un plazo - de hasta seis meses-a uno de ellos para que pudiera recuperar el dinero efectuando las diligencias necesarias. En caso de no poder hacerlo las pérdidas afectarían en la misma proporción a los compañeros ${ }^{51}$. También podía exigirse a uno de los socios que pagase las deudas debidas y "sacase a paz y a salvo" al otro una vez concluido el negocio, es decir, que le liberase de posibles responsabilidades. En el caso de no haber conformidad entre partes a la hora de finiquitar las cuentas podía recurrirse a un tercero para que dictaminase al respecto ${ }^{52}$. De no "ser fenecidas" en el plazo establecido podían imponerse penas de carácter espiritual. En la compañía entre Juan de Junta y Alejandro de Cánova se estipularon 300 misas por las almas del purgatorio que debería pagar la parte incumplidora $^{53}$. Aunque la distribución de beneficios se realizaba a la finalización de la compañía, durante su período de vigencia, como ya hemos apuntado, alguno de los

46 De las mujeres que formaron parte de las compañías sólo dos de ellas supieron firmar los documentos. Se trataba de esposas de libreros. De los varones lo hicieron casi tres cuartas partes. Como sucedía en Zamora, el porcentaje de alfabetización entre los mercaderes masculinos y sus asociados fue bastante elevado. A.H.P.Sa. P.N. Leg. 2946. 6-IV-1571. Fols. 539-543; Leg. 3370. 21-I-1551. Fols. 423-424; Leg. 3667-7-XI-1590. Fols. 761-762; Leg. 4870. 1-VI-1589. Fol. 1304.

48 A.H.P.Sa. P.N. Leg. 3226. 3-XI-1600. Fols. 311-312.

49 A.H.P.Sa. P.N. Leg. 4867. 5-V-1586. Fols. 397-398.

50 A.H.P.Sa. P.N. Leg. 2924. 3-XI-1532. Fols. 33-36.

51 A.H.P.Sa. P.N. Leg. 2946. 6-IV-1671. Fols. 539-543.

52 A.H.P.Sa. P.N. Leg. 3872. 17-XII-1547. Fols. 170.

53 A.H.P.Sa. P.N. Leg. 2924. 3-XI-1532. Fols. 33-36. 
socios podía disponer de parte del capital para ayuda de su mantenimiento y del de su familia ${ }^{54}$; para cambiar su estado civil -si se trataba de viudas-, o para la adquisición de una vivienda aunque siempre hasta determinada cuantía ${ }^{55}$.

Tanto la ejecución de las cuentas como los porcentajes de participación no siempre se mantuvieron en el marco de unos parámetros claramente establecidos, en algún caso por la posible confianza existente entre los socios quienes manifestaron cierta desidia al respecto. Esta circunstancia obligó a recurrir a determinados acuerdos a la hora de efectuar el balance. Juan María de Terranova y Jacobo de Liarcari, mercaderes de libros, habían fundado una compañía en el año 1549 y, ocho años después, en 1557, al acudir al escribano, alegaron que cuando la establecieron "no se tomó asiento por tiempo cierto y limitado ni se declaró la parte que cada uno aportó en ella, ni lo que había de haber y participar de la ganancia o la pérdida”. Acordaron que de lo que comercializaran en la villa de Medina del Campo Juan María recibiese tres quintas partes y su socio el resto, y del capital en efectivo de cualquiera de ellos y que no procediese de la compañía se le asignase un interés a razón de 14.000 el millar, es decir, al 7,1 por ciento. El dinero que hubiesen sacado de la compañía, salvo el necesario para el trato y vestido, lo devolverían a un interés del 12 por ciento ${ }^{56}$. Los libreros Alejandro de Cánova y Juan de Junta a la hora de la liquidación de su compañía, tras dos décadas de colaboración, se vieron obligados a recurrir a la "vía de transacción" para evitar pleitos ya que no habían llevado una contabilidad rígida debido a la amistad entre ambos ${ }^{57}$.

A pesar de la aparente confianza que debiera existir entre los socios a la hora de afrontar juntos un negocio, no faltaron en los contratos cláusulas que intentaron delimitar la forma de proceder de los compañeros, aun cuando fuesen familiares, y ofrecer garantías ante posibles desfalcos. De este modo, se llegó a exigir al socio dar "cuenta fiel y verdadera con juramento de lo comprado y vendido" tanto al contado como al fiado 58 ; que se comprometiese a "no encubrir u ocultar cosa alguna"59;

54 A.H.P.Sa. P.N. 2946. 6-IV-1571. Fols. 539-543; Leg. 4614. 20-IX-1575. Fols. 1805-1808; Leg. 4616. 11-I-1576. Fols. 1653-1654.

55 Inés de Canillas, viuda, permitió a su yerno Juan Rodríguez que pudiera disponer de hasta 200 ducados, o lo que hubiere de ganancias hasta ese momento si salía alguna casa en venta en la Calle la Rúa. En el caso de que ella desease meterse monja o casarse se le permitirían tomar hasta 50.000 maravedíes, probablemente para ayuda del pago de su dote. Además, podrían comprar vestidos para sus personas, hijos y criados del dinero de la tienda obligándose a registrarlo en los libros. A.H.P.Sa. P.N. Leg. 2921. 5-VII-1527. Fols. 510-513; Leg. 2924. 3-XI-1532. Fols. 33-36.

A.H.P.Sa. P.N. Leg. 2934. 3-IV-1557. Fols. 439-442.

A.H.P.Sa. P.N. Leg. 2937. 24-V-1550. Fols. 530-531 y 6-IV-1560. Fols. 381-406.

En la de Lázaro Hernández, cordonero, y su mujer, María Palencia, con Catalina de Ávila se indica que además del asiento de las cuentas se les tomaría juramento "de que no recetarán ni encubrirán cosa alguna de lo que costaren las mercadurías". En esta compañía no se permitía al socio la venta al fiado. A.H.P.Sa. P.N. Leg. 3392. 11-III-1590. Fols. 583-586.

A.H.P.Sa. P.N. Leg. 4616. 11-I-1576. Fols. 1653-1654. 
que "tratase en ella [con] toda legalidad e verdad y nos hemos de tratar e comunicar como amigos e compañeros sin que ninguno pueda hacer al otro fraude o colusión alguna" 60 ; que las compras se efectuasen con claridad, sin cautela, fraude o engaño"; que presentase fiadores o que pusiese como fianza su vivienda o el ganado de su propiedad ${ }^{61}$. En esta línea puede también interpretarse la existencia de arcas con múltiples cerraduras que se abrían en presencia de todos los socios. Cada uno de ellos contaba solamente con una llave de una de las cerraduras ${ }^{62}$. En la compañía entre Juan González y Francisco de Almaraz se procedió del siguiente modo:

... por una abertura se ha de echar todo el dinero que cayere y quando se sacare se saque por escripto y se ponga en un libro que para ello haya; y cada uno de nos para nuestro gasto hordinario y para el atavío de nuestras personas y jente podamos sacar de la dicha arca lo que hubiéremos menester poniéndolo por escripto, e para otra cosa fuera de lo que fuere menester para el dicho trato no hemos de sacar otra $\operatorname{cosa}^{63}$.

De cara a garantizar la transparencia de las actuaciones, ocasionalmente en las renovaciones de los contratos se determinó un plazo corto con el objeto de que los socios "so cargo de sus conciencias y del juramento que el uno al otro se haga" presentasen "memoria firmada de su nombre de todas las escrituras que tienen públicas o privadas que toquen a la compañía hasta el día de la fecha para que por ellas se pueda cobrar y se sepa lo que se cobra" ${ }^{6}$.

\section{El objeto social de las compañías}

Las compañías dedicadas al trato de ganado constituyeron las sociedades mercantiles más habituales en la urbe salmantina representando casi cuatro de cada diez de las fundadas; no obstante, esta cifra puede ofrecernos una visión distorsionada de la actividad comercial ya que se trata de negocios de escaso volumen y capital monetario -osciló entre los 200 y los 1.650 reales (ver tabla 3)- lo que permitió en ocasiones que una misma persona llegase a fundar hasta nueve en un mismo año. Generalmente un vecino de la urbe solía entregar a otro u otros de la zona agraria

60 A.H.P.Sa. P.N. Leg. 3650. 7-II-1550. Fols. 104-105.

61 A.H.P.Sa. P.N. Leg. 2929. 5-XI-1548. Fols. 227-230; Leg. 3155. 22-IX-1546. Fol. 293; Leg. 3662. 30-VI-1579. Fols. 434-435; Leg. 4849. 21-XI-1562. Fol. 489; Leg. 4634. 30-IX-1584. Fols. 23072310; Leg. 5086. 5-XII-1585. Fols. 1025-1026; Leg. 5260. 8-VII-1588. Fols. 1269-1270 y 11-IV1588. Fols. 1337-1338.

62 A.H.P.Sa. P.N. Leg. 5307. 26-XII-1581. Fols. 930-931.

63 Leg. 5248. 21-IX-1574. S.f.

${ }_{64}$ A.H.P.Sa. P.N. Leg. 2924. 3-XI-1532. Fols. 33-36. 
salmantina una cantidad de dinero para que en un plazo corto de tiempo -mínimo de mes y medio- o en una determinada feria -la de Medina del Campo- adquiriese las reses. Una de las personas más activas en este negocio, la ya citada Susana Hernández, dejaba patente en sus contratos cómo debía movilizarse el capital en efectivo invertido: “... que el dicho dinero no esté de más, sino siempre empleado, comprando y bendiendo para que siempre gane y no se pierda por causa de no lo emplear" ${ }^{65}$.

Los socios del ámbito rural además de la obtención del ganado se encargaban de alimentarlo, de su custodia y del pago de los portazgos ${ }^{66}$. El dinero para la adquisición y cuidado de los animales se sacaba del fondo de las compañías, o, como indicaban las fuentes, se "escalfaba" ${ }^{67}$. El pasto de los animales podía prolongarse hasta una época en la que el ganado tuviese los precios más elevados. Isabel Pacheco, vecina de Salamanca, estableció un acuerdo con Antonio Hernández, vecino de Tamames, por el cual le entregaba 2.077 reales:

... para que pueda comprar puercos este presente año en cualquier parte que los hallare y al precio que le pareciere y los meta a dehesa, yerba, bellota y zevo, ora sea en el monte de Castro, que él tiene arrendado, o en otra dehesa, y los venda a su tiempo, que es por San Andrés o cuando mejor venta haya, antes o después, con que no pase de mediado del mes de diciembre primero que vendrá ${ }^{68}$.

Excepcionalmente hallamos alguna compañía en la que la persona residente en la urbe salmantina era quien compraba los animales y la del medio rural los cuidaba. Isabel Maldonado, viuda del licenciado Martínez, adquirió 48 borregos a precio de 10 reales y cuartillo cada uno que se encargaría de alimentar un tal Hernando Pardo, vecino de Carbajosa de la Armuña. Si se perdiese algún animal por culpa o negligencia de este último, correría por su cuenta, pero si la res moría sería a costa de ambos socios. Descontado el precio de la adquisición, los beneficios - tanto de la lana como del animal- se dividían entre ambas partes ${ }^{69}$. Lo mismo sucedió con Pedro Sánchez, vecino de Salamanca, quien compró 119 ovejas a cinco reales cada una y se las dio a criar a Miguel Cañizo, vecino de Carbajosa de la Sagrada. El ganado tendría que ser marcado en el lado derecho - con una señal de este estilo: /0/ -; se vendería con licencia de Pedro y se repartirían el beneficio del esquilmo entre los socios. El pago de los ordeñadores se descontaría de la parte de Miguel. En el caso de fallecer alguna oveja este último estaba obligado a presentar los pellejos como prueba de la muerte. Si la

A.H.P.Sa. P.N. Leg- 5086. 2-V-1585. Fols. 1007-1026.

A.H.P.Sa. P.N. Leg. 4694. 21-V-1599. Fols. 1223-1224.

A.H.P.Sa. P.N. Leg. 3139. 28-V-1534. Fol. 372; Leg. 3666. 17-XI-1587. Fols. 818-819.

A.H.P.Sa. P.N. Leg. 3662. 30-VI-1579. Fols. 434-435.

A.H.P.Sa. P.N. Leg. 4855. 26-IV-1571. Fols. 416-417. 
carne del animal finado era aprovechable "sería por cuenta del principal", es decir, entraría en el monto de los beneficios ${ }^{70}$.

Los capitalistas salmantinos que invirtieron en este negocio no estuvieron necesariamente relacionados con el mundo de la ganadería y procedieron de profesiones diversas (dos canteros, un licenciado, un impresor, un bordador, un carpintero, un mercader, un zapatero y la viuda de un sastre). Aunque los primeros solían poner el mayor volumen de capital en efectivo e incluso eran los únicos aportantes del mismo, los beneficios solían repartirse a medias para compensar el trabajo del compañero, o como se expresaba en las fuentes: su "deligençia, yndustria e solicitud" 71 . Los socios de la zona rural solían proceder de Fuente el Roble, Salvatierra, Los Villares, Pelabravo, San Pedro de Rozados, Carbajosa de la Armuña, Tamames, Tabera, Cabrerizos, Forfoleda, Juzbado, Machacón, Carbajosa de la Sagrada, La Alberca, Monterrubio de la Armuña, Mozodiel de Sanchínigo, y, mayoritariamente, de Castellanos de Villiquera. Sobre el ganado objeto de comercialización se mencionan carneros, cabras, borregos, ovejas, corderos, puercos, lechones, bueyes y vacas aunque sin precisar cifras por lo cual resulta imposible delimitar cuáles fueron los animales más demandados ${ }^{72}$. Este tipo de compañías no mantiene en su forma de proceder relación con los contratos de aparcería donde un propietario de ganado entregaba a un individuo las reses para su cuidarlo a cambio de unos beneficios. Quienes participaron en este tipo de empresas no eran propietarios de animales sino que se limitaron a proporcionar el capital necesario para adquirirlos e incluso no supervisaron las ventas sino que las dejaron al buen criterio de su socio.

Las del ámbito textil representaron una de cada cuatro compañías entre las constituidas. El capital monetario invertido fue superior al de las compañías dedicadas al trato de ganado oscilando entre los 588 reales y los 17.800 reales -ver tabla 3En ellas no sólo participaron mercaderes sino también algún licenciado, ballestero, cabritero o clérigo que demandaban a los profesionales del comercio que pusiesen "la diligencia y cuydado posibles de suerte que se pueda antes ganar que perder" 73 . Se dedicaron a la comercialización de paños, seda, telas, calcetería y cordonería. Podemos conocer algunos de los objetos de venta, caso de los relacionados con los roperos, gracias a los escasos memoriales de bienes presentados ante el escribano a la hora de su fundación. Este sector trabajaba con ropas -chamarras, capas, capotes,

\footnotetext{
70 A.H.P.Sa. P.N. Leg. 3668. 23-V-1592. Fols. 229-230.

71 A.H.P.Sa. P.N. Leg. 2914. 6-III-1519. Fol. 280; Leg. 4854. 21-XI-1569. Fols. 305-306; Leg. 5249. 29-X-1575. Fols. 1046-1047.

72 A.H.P.Sa. Leg. 4858. 22-IV-1574. Fols. 426-427; Leg 4640. 7-V-1587. Fols. 2350-2351.

73 En algunas compañías se especificaba que el trato debería ejercerse sólo con determinados animales. A.H.P.Sa. P.N. Leg. 3663. 31-VIII-1579. Fols. 588-591.
} 
mantos, sayos, sotanas, ropas de contray, cuerpos, mangas, muslos, zamarros, mantas-, maderas y objetos de camas -colchones, jergones, doseles, sábanas-, muebles de casa - mesas de comer, de estudio, bancos, sillas, cajas de braseros, arcas- e incluso con libros, probablemente de segunda mano ${ }^{74}$. Este tipo de documentación pone de relieve cómo los mercaderes de ropa poseían un elenco de mercancías mucho más amplio de lo que su denominación pudiera sugerir. Para poder ofertar al público este material había en ocasiones que restaurarlo. El hilo, la seda, los "adobos" necesarios para hacer y deshacer las ropas, así como la cera y velas utilizadas para trabajar por la noche y parte de los impuestos de su comercialización -alcabalas- solían correr por cuenta de la compañía. Aunque el socio debía limitar sus ventas a las de la sociedad se hicieron excepciones de manera que se permitió a alguno de ellos comercializar con determinados productos textiles - mantas frazadas, cobertores o ropa de camapara beneficio personal ${ }^{75}$.

Alguna de las compañías de este ámbito ejerció tanto funciones comerciales como de transformación del producto. Sucedió con la formada por Pedro Hernández, El Mozo, vecino de la Alberca, quien había tomado la colambre -pellejos- de la carnicería donde residía, y Francisco García, vecino de Salamanca, mercader de ropas. Este último le entregó 3.000 reales para la compra de los cueros vacunos y caprinos a cambio de que Pedro se encargarse de curtirlos empleando a los oficiales que fuesen necesarios, y de llevar el libro de cuentas - a pesar de que no sabía firmar-. Recibiría el salario de un oficial y la mitad de las ganancias. Se presupone que se procedería por parte de la compañía a la venta del género curtido ${ }^{76}$. La ciudad de Salamanca poseía durante este siglo varias manufacturas en las riberas del puente donde se elaboraron diferentes curtidos (suelas, cordobanes y becerros) ${ }^{77}$. Este caso de incursión de mercaderes en la producción manufacturera constituye una excepción dentro de la línea de actuación de las compañías mercantiles salmantinas. Como podemos apreciar y al igual que sucedía en otras ciudades, caso de Madrid, la inversión en capital fue modesta, probablemente limitada a la que necesitaba el trabajo artesanal, manteniendo de este modo los talleres un bajo grado de capitalización ${ }^{78}$. A falta de la consulta de otro tipo de documentación no podemos afirmar que existiese una sólida implantación de los mercaderes en aspectos fundamentales para el desarrollo de la industria textil, que hubiese una fuerte dependencia de los artesanos del ramo

A.H.P.Sa. P.N. Leg. 2929. 5-XI-1548. Fols. 227-230; Leg. 5458. 31-I-1586. Fols. 199-210.

A.H.P.Sa. P.N. Leg. 5248. 21-IX-1574. S.f.

A.H.P.Sa. P.N. Leg. 4674. 28-II-1596. Fols. 933-934.

LLOPIS, S.: Op. cit. p. 67.

ZOFÍO LLORENTE, J.C.: Gremios y artesanos en Madrid, 1550-1650. La sociedad del trabajo en una ciudad cortesana preindustrial, Madrid, C.S.I.C., 2005, p. 160. 
respecto al capital comercial o un desarrollo de actividades protoindustriales, caso de lo acaecido en Córdoba o en Madrid en el siglo XVI ${ }^{79}$.

El tercer grupo de sociedades por su presencia numérica - una de cada diez de las presentes en la urbe- estuvo relacionado con el mundo del libro $^{80}$. En este sector predominaron las sociedades establecidas por individuos extranjeros, aunque no faltaron tampoco las integradas exclusivamente por mercaderes salmantinos ${ }^{81}$. La participación de individuos de otros países en la formación de compañías resultó más habitual en zonas costeras que en el interior o en lugares donde se llevaban a cabo ferias importantes como la de Medina del Campo ${ }^{82}$. Tal vez la más relevante por el número de socios y el alcance internacional de sus negocios fue la establecida en 1530 por diversos libreros de la urbe con Gaspar Trechsel, lionés, y Lorenzo Anticeno, alemán, vecino de Medina del Campo. Estuvo también integrada por los italianos Juan de Junta y Lorenzo de Lion de Dey, el borgoñés Alejandro de Cánova, Juana Maldonado, viuda de Jusquin Lecarón, su hijo Martín de Lecarón, Alonso de Ribas, Úrsula Martínez y su hijo Cristóbal de Pascua, Gasparo Ruyseñolis, de posible origen italiano, Bernardino de Castronovo, milanés, y Blas de Vergara, todos ellos vecinos de Salamanca. Esta asociación tuvo por objeto la adquisición de ediciones internacionales a los mejores precios posibles. Aunando capitales podía adquirir al por mayor la mercancía en los lugares de producción salvando costes y trámites minoristas delegados por las casas editoriales para la distribución de sus productos. Conseguían, así mismo, un abastecimiento más fluido sin estar limitados por el marco temporal de las ferias. Los libros eran enviados desde Lyon por Gaspar Trechsel depositándose en las tiendas de Medina del Campo, a cargo de Lorenzo Anticeno, y Salamanca para distribuirse entre los miembros de la compañía quienes no podían realizar compras de

79 J.A. Nieto Sánchez y Victoria López, apuntan, no obstante, que la producción textil en Madrid siguió desarrollándose mayoritariamente en pequeños talleres descapitalizados. FORTEA PÉREZ, J.I.: Córdoba en el siglo XVI: Las bases demográficas y económicas de una expansión urbana, Córdoba, Monte de Piedad y Caja de Ahorros de Córdoba, 1981, pp. 358 y 376; NIETO SÁNCHEZ, J.A.: Artesanos y mercaderes. Una historia social y económica de Madrid (14501850), Madrid, Editorial Fundamentos, 2006, pp. 118-119 y "NIETO SÁNCHEZ, J.A. y LÓPEZ BARAHONA, V.: "La formación de un mercado de trabajo: las industrias del vestido en Madrid en la Edad Moderna", Sociología del Trabajo, 68, 2010, p. 150.

80 Vicente Bécares nos ofrece una relación de los documentos conservados para el mundo editorial salmantino referentes a este siglo. BÉCARES BOTAS, V.: Avance para una guía del mundo del libro salmantino del siglo XVI, Zamora, Ediciones Monte Casino, 2002.

$81 \quad$ Fue el caso de la fundada por Luis Méndez y Francisco de León quienes además de negociar con libros invirtieron en censos. A.H.P.Sa. Leg. 3657. 27-I-1570. Fols. 96-99.

82 En el caso de Cartagena los mercaderes nativos enriquecidos no pasarían a tomar el protagonismo frente a los extranjeros hasta las dos últimas décadas del siglo XVI. Ver VELASCO HERNÁNDEZ, F.: "Capitalismo y burguesía mercantil; el puerto de Cartagena en el período 1560-1630", Contrastes. Revista de Historia Moderna, Nos 5-6, 1989-1990, p. 23. 
libros fuera del marco de la sociedad. Mientras Gaspar percibía un sueldo por su trabajo, Lorenzo recibía por la gestión de las ventas una comisión del 5 por ciento y una ayuda para mantener una cabalgadura que facilitase sus desplazamientos. ${ }^{83}$ Apenas cuatro años después de comenzada su andadura la compañía fracasaría por las irregularidades de Trechsel quien elevó el coste de los libros por encima del porcentaje habitual, no llevó una contabilidad adecuada ni informó a sus compañeros, envió obras defectuosas, vendió libros a personas ajenas a la compañía y sufrió grandes pérdidas de capital a causa de las confiscaciones a las que le sometió la autoridad española por sus intentos de introducir seda y moneda de contrabando.

Paralelamente a la compañía anterior, Juan de Junta y Alejandro de Cánova mantuvieron otra que se valió de parte de las prensas que el primero tenía en Burgos para imprimir en Salamanca. No sólo compartieron profesión sino también domicilio. Se distribuyeron la casa en que vivían para habitar ambas familias e instalaron en la planta baja sus aparejos de trabajo ${ }^{84}$. Se dedicaron a la impresión y venta de libros -operando en Burgos, Medina del Campo, Valladolid o Sevilla, entre otras zonas- e igualmente a la joyería, arrendamientos y venta de pan ${ }^{85}$. De manera similar trabajaron Juan María de Terranova, italiano, vecino de la villa de Medina del Campo, quien acabaría asentándose en la urbe salmantina, y Jacobo de Liarcari, de la misma nacionalidad, dedicados tanto al mundo editorial como a la compra-venta de joyas y de otros objetos lo cual les permitió adquirir bienes raíces tanto en Castilla como en Aragón y Valencia ${ }^{86}$. Los mercaderes de libros Juan de Junta y Martín de Carón, junto con un tal Alonso Cornejo, ampliaron sus negocios del libro con la trata de ganado ovejuno que tenían en las dehesas de La Sauceda y La Torrecilla, en tierra de Coria ${ }^{87}$.

Si a los anteriores les había unido la amistad o unos intereses comunes para afrontar los negocios, en otros casos encontramos en las compañías una vinculación "endotécnica" y consanguínea, caso de la de Lucrecia de Junta, viuda de Matías Gast, flamenco, con sus yernos Cornelio Bonart y Diego de Robles. Con la colaboración de Julio de Junta se encargaron de parte de la impresión y de la distribución de los libros del Nuevo Rezado - misales, breviarios, diurnos o diurnales, horas y pasionarios, entre otros- de los cuales tenían la patente los jerónimos de San Lorenzo del Escorial. Exportaron desde la ciudad salmantina a México algunas partidas de

83 Esta compañía ha sido estudiada por Marta de la Mano y Vicente Bécares Botas de quienes tomamos los datos aportados en este estudio. MANO GONZÁLEZ, M. de la: Mercaderes e impresores de libros en la Salamanca del siglo XVI, Salamanca, Universidad de Salamanca, 1998. BÉCARES BOTAS, V.: La compañia de libreros de Salamanca (1530-1534), Salamanca, SEMYR, 2003.

84 A.H.P.Sa. P.N. Leg. 2924. 3-XI-1532. Fols. 33-36.

85 A.H.P.Sa. P.N. Leg. 2937. 24-V-1550. Fols. 530-531.

86 A.H.P.Sa. P.N. Leg. 2934. 3-IV-1557. Fols. 439-442.

87 A.H.P.Sa. P.N. Leg. 3137. 10-III-1531. Fol. 63. 
estos libros. También importaron habitualmente obras directamente desde Venecia o a través de mercaderes italianos afincados en Medina del Campo; además diversificaron su negocio con el trato de telas y hierro ${ }^{88}$. En cuanto a la participación de los salmantinos en este ámbito, además de la compañía formada en la década de 1530 , a la que ya hemos aludido, cabría citar la de Gaspar de Novela con Juan Moreno y Beatriz Rodríguez. El primero, que había sido administrador de la tienda de Juan, se encargaría de todo el negocio aunque los beneficios se repartirían a partes iguales ${ }^{89}$. Las compañías en las que intervinieron extranjeros siguieron tendencias similares a las de otros puntos europeos donde las redes comerciales se edificaban sobre un sistema en el cual los factores de las tiendas estaban íntimamente ligados a través de la parentela a las casas matrices ${ }^{90}$.

Algunas de las sociedades del ámbito editorial tuvieron una vida efímera y se crearon simplemente para financiar la impresión de un libro concreto. Fue el caso de la fundada por Domingo de Portonaris, impresor, Vicencio de Portonaris, mercader de libros, y Juan Díez, mercader de paños, vecinos de la ciudad de Salamanca, que se unieron para editar un libro -probablemente Opera Omnia- de don Diego de Covarrubias y Leyva, presidente del Consejo Real y obispo de Sevilla. La impresión se realizaría en las prensas de Domingo. Vicente y Juan se encargarían de proporcionar el papel de marquilla y asumirían los gastos de la tinta y otros aderezos de la imprenta, así como el salario de los oficiales. Las obras impresas se entregarían a Juan para que él las vendiese. Debería plasmar en el libro de razón los ejemplares vendidos, los cuales no se darían al fiado a no ser por consentimiento de los tres. Los primeros ingresos obtenidos se destinarían al pago de los gastos de la impresión y una vez cubiertos, los beneficios se repartirían entre los tres socios a partes iguales. No se podría efectuar otra impresión hasta que solamente quedasen 100 libros por vender de los $1.250 \mathrm{im}$ $\operatorname{presos}^{91}$. El mismo propósito persiguió la de Gaspar de Portonaris, mercader e impresor de libros, con Benito Boyer, librero de Medina del Campo, y Guillermo Rubillo, vecino de Lyon. Los dos últimos acordaron participar en la impresión de la Biblia de Vatablo, que había iniciado el primero, sufragando los costes a cambio de la mitad de

A.H.P.Sa. P.N. Leg. 3203. 7-V-1584. Fols. 131-173.

Juan había tenido previamente una compañía con Benito Boyer, mercader de libros francés asentado en Medina del Campo, entre los años 1570 y 1574 . Tras el fallecimiento de Gaspar y de Juan, Beatriz fundaría otra compañía con Octaviano Parente. A.H.P.Sa. P.N. Leg. 4620. 3-VIII1578. Fols. 1559-1561; Leg. 5075. 12-VIII-1574. Fol. 879; Leg. 4620. 3-VIII-1578. Fols. 15591561 y 12 -VIII-1574. Fols. 877-878 y 881-882.

FONTAINE, L. y SIDDLE, D.: "Mobility, kinship and commerce in the Alps, 1500-1800", en SIDDLE, D. J. (Ed.), Migration, mobility and modernization, Liverpool, Liverpool University Press, 2000, p. 6.

A.H:P.Sa. P.N. Leg. 5247. 14-IX-1575. Fols. 137-142. 
los beneficios. Aunque Benito Boyer quedaría como depositario de la edición, se acordó que los primeros pliegos de ella se introdujesen en un arca y se irían sacando cien para cada parte a medida que se fuesen vendiendo. Hasta no completar cada uno de los libreros la venta total de sus libros no se procedería a otra extracción de pliegos $^{92}$. Las compañías de libreros citadas en este trabajo no fueron las únicas que operaron en Salamanca. Desgraciadamente no se han conservado sus escrituras fundacionales entre los protocolos salmantinos y tal vez alguna pueda localizarse en otra ciudad. Solamente contamos con referencias sesgadas sobre su actividad ${ }^{93}$.

Respecto al resto de las sociedades, en unos casos comercializaron con un único producto -zumaque ${ }^{94}$, cera, hierro ${ }^{95}$, madera o pescado- o con una disparidad de ellos -fruta y telas; mercería e imaginería; dinero y "otras cosas"; o cebada, pescado y aceite ${ }^{96}$-. De cualquier modo no resulta fácil establecer una tipología completa de las actividades a las que se dedicaron las compañías ya que una de cada ocho no lo indicó remitiéndose en la escritura notarial a las habituales fórmulas de "cosas necesarias", "cosas líçitas y honestas", "tratos lícitos"; "cualquier trato" o "mercaduría", "en lo que mejor y más acertado sea para el ynterés de ella", expresiones propias de las denominadas compañías universales ${ }^{97}$. A tenor de la opinión de algunos especialistas estaríamos ante comerciantes abiertos a cualquier posibilidad y sociedades mercantiles adaptables a cualquier circunstancia económica ${ }^{98}$. Otras, como ya hemos señalado, aunque desarrollaron una actividad de manera prioritaria no descartaron la

\section{A.H.P.Sa. P.N. Leg- 3201. 22-XII-1583. Fols. 642-650.}

Poseemos noticias, a través de otro tipo de documentación, de la compañía establecida por ejemplo entre Juan de Junta, Lorenzo de León de Dei y Alonso de Rivas; de la realizada entre Matías Gast y Lucas de Junta, quienes compraron los derechos del mercader de libros Benito Boyer, vecino de Medina del Campo, para editar las obras de Domingo de Soto; o de la formada por los hermanos Felipe, vecino de Burgos, y Julio de Junta. A.H.P.Sa. P. N. Leg. 3139. 20-V-1534. Fol. 238; Leg. 3187. 17-XII-1574. Fols. 602-604; Leg. 3189. 20-VIII-1576. Fols. 461-464.

94 El zumaque se empleaba para el curtido del cuero. A.H.P.Sa. P.N. Leg. 4612. 26-IX-1572. Fol. 1742 .

$95 \quad$ Era traído de Vizcaya. Leg. 3881. 7-VIII-1597. Fols. 304-305.

96 A.H.P.Sa. P.N. Leg. 4631. 1-VIII-1572. Fols. 2068-2069.

${ }_{97}$ Así las denomina Antonio García-Baquero o Isabel Lobato Franco, entre otros. GARCÍA.BAQUERO GONZÁLEZ, A.: Cádiz y el Atlántico (1717-1778). (El comercio colonial español bajo el monopolio gaditano), Tomo I, Cádiz, Escuela de Estudios Hispano-Americanos, 1976, p. 434. LOBATO FRANCO, I.: Op. cit., p. 128; A.H.P.Sa. P.N. Leg. 4861. 26-IV-1577. Fols. 654-655; Leg. 5250. 16-III-1576. Fols. 224-225. CAUNEDO DEL POTRO, B.: "Comercio y hombres de negocios castellanos en tiempos de los Reyes Católicos. Técnicas y aprendizaje”, en CASADO ALONSO, H. y GARCÍA-BAQUERO, A.: Comercio y hombres de negocios en Castilla y Europa en tiempos de Isabel la Católica. Madrid, Sociedad Estatal de Conmemoraciones Culturales, 2007, p. 262 y CASADO ALONSO, H.: "Comercio, crédito y finanzas públicas en Castilla en la época de los Reyes Católicos", en BERNAL RODRÍGUEZ, A.M. (Coord.): Comercio, crédito y finanzas públicas en Castilla en la época de los Reyes Católicos, Madrid, Fundación ICO-Marcial Pons, 2000, p. 141. 
diversificación, caso de los libreros que también actuaron de arrendadores de rentas eclesiásticas y comercializaron con joyas o pan; o los roperos, que también tuvieron negocios en el mercado de las joyas.

\section{La disolución de las compañías}

Como ya hemos indicado, las sociedades mercantiles se establecieron habitualmente con un plazo de vigencia limitado que podía quedar alterado en caso de fallecimiento de alguno de los compañeros o "por cosa tan fea por que no se deva de tener compañía"99. Aunque no resultaba habitual, si se abandonaba arbitrariamente la sociedad antes del tiempo estipulado esta circunstancia podía estar penalizada económicamente ${ }^{100}$. En la de Cristóbal de Tapia, vecino de Salamanca, y Juan de Ayala, vecino de Valladolid, merceros, la sanción ascendía a 10 ducados -110 reales- cifra considerable si tenemos en cuenta que Juan había aportado a la compañía 128 reales. La totalidad de la multa iría destinada al socio cumplidor ${ }^{101}$. En la del ropero Gabriel de Villaria y el cabritero Juan de Manganeses el infractor perdería las ganancias obtenidas hasta ese momento ${ }^{102}$. La marcha de uno de los compañeros implicó en ocasiones el deseo de desligarse algún otro de los socios de la compañía alegando que la sociedad se había formado bajo un número determinado de individuos. Esta alteración suponía una modificación en el capital monetario a aportar y, por consiguiente, existía el miedo a afrontar un mayor número de riesgos. De no haber consenso entre los socios el asunto acababa en los tribunales donde se exigía la fiscalización de las cuentas para delimitar pérdidas o ganancias ${ }^{103}$.

Excepcionalmente se dieron situaciones por las cuales el socio capitalista podía retirar su capital monetario cuando desease y dar por disuelta la compañía. El cordonero Lázaro Hernández y su mujer María de Palencia, recibieron 835 reales de Catalina de Ávila para que los empleasen en el trato de cordonería. Deberían efectuar cuentas cuatrimestralmente pero si esta última quería "alçarse de la dicha compañía y tomar y llebar su dinero para lo que ella quisiere" y estarían obligados a darle cuenta y pagárselo al contado ${ }^{104}$.

\footnotetext{
99 A.H.P.Sa. P.N. Leg. 2912. 5-VIII-1516. Fols. 1081-1084; Leg. 2925. 5-IX-1533. Fol. 280-281.

100 En la de Juan González y Francisco de Almaraz, mercaderes, con 200 ducados. La de Bartolomé y Lucas de Mora, mercaderes, se estipuló en 50 ducados. A.H.P.Sa. P.N. Leg. 5248. 21-IX-1574. S.f.; Leg. 5250. 9-VI-1576. Fols. 1118-1119.

101 A.H.P.Sa. P.N. Leg. 2935. 24-XII-1558. Fol. 1281-1282.

102 A.H.P.Sa. P.N. Leg. 2946. 6-IV-1571. Fols. 539-543.

103 A.R.Cha.V. Registro de Ejecutorias. Caja 1450, 27. Ejecutoria del pleito litigado por Tomás Cuello con Nicolás Cañete, vecinos de Salamanca. 19-IX-1581.

104 A.H.P.Sa. P.N. Leg. 3392. 11-III-1590. Fols. 583-586.
} 
Tras el periodo de operaciones se procedía a la realización del balance y cuando alguno de los compañeros resultaba "alcanzado", es decir, deudor del otro, se establecía un plazo para la devolución de la cantidad adeudada que podía oscilar desde unos días hasta los cinco meses. En algún contrato se fijaba que tal alcance no pudiera saldarse en género o en deudas debidas a la compañía ${ }^{105}$; o se estipulaba que su cuantía se pagase en moneda de plata, probablemente para evitar los efectos de la inflación ${ }^{106}$. En otras, como las de los roperos, en las cuales se habían aportado géneros para comercializar a la hora de su fundación, cada una de las partes estaba obligada a tomar lo que no se hubiere vendido tasándose el material por dos personas ajenas a la compañía, una nombrada por cada parte; o a fraccionar el capital social en tres partes -capital en efectivo, género y deudas- entregando a cada socio lo que le correspondiese, aunque no se trató de un procedimiento aplicable a todos los casos ${ }^{107}$. El cobro de las deudas pendientes certificadas a través de obligaciones, cédulas y libros de cuentas podía quedar a cargo del administrador de alguna de las tiendas de la compañía a cambio de una comisión. Gaspar de Noveda -o Novela-, al servicio del librero Juan Moreno, percibiría un 5 por ciento de todas las que pudiere cobrar de la sociedad que había disuelto su señor y Benito Boyer ${ }^{108}$.

Tanto la devolución del capital monetario al socio capitalista una vez finiquitada la compañía, como el pago de los "alcances" derivados de la realización de las cuentas fueron aspectos que no estuvieron exentos de problemas. La negativa a realizar las cuentas o a pagar los beneficios obtenidos por parte de uno de los socios, los retrasos en su abono o el deseo de entregar parte de las ganancias en mercancías constituyeron algunas de las causas que tensaron las relaciones entre los compañeros y derivaron en litigios ${ }^{109}$. La justicia solía intervenir si se dilataba la presentación de las cuentas compeliendo al nombramiento de contadores, uno por cada parte junto con un tercero en caso de discordia ${ }^{110}$. Ante la sospecha de huida del socio insolvente -"no abonado"- se solicitaba su encarcelamiento y la presentación de fiadores para poder abandonar la prisión"111. En ocasiones, aunque se le otorgaba al socio "alcanzado" una carta de pago y finiquito sobre el capital adeudado al cierre del balance, en realidad no se había efectuado dicho pago generando igualmente pleitos ante los tribunales. La recuperación parcial de este capital podía efectuarse cuando el socio

A.H.P.Sa. P.N. Leg. 2912. 5-VIII-1516. Fols. 1081-1084; Leg. 2913. 21-XII-1517. Fols. 153-155.

A.H.P.Sa. P.N. Leg. 4868. 12-III-1587. Fols. 240-241 y 21-VIII-1587. Fols. 280-281.

A.H.P.Sa. P.N. Leg. 2929. 5-XI-1548. Fols. 227-230; Leg. 2921. 5-VII-1527.Fols. 510-513.

A.H.P.Sa. P.N. Leg. 5075. 12-VIII-1574. Fols. 881-882.

A.R.Ch.Va. Registro de Ejecutorias. Caja 298, 32. 27-X-1514; Caja 239, 23. 31-VIII-1509.

A.R.Ch.Va. Registro de Ejecutorias. Caja 1714, 49. 15-IV-1592.

A.R.Ch.Va. Registro de Ejecutorias. Caja 332, 29. 29-X-1518.
} 
deudor en su testamento, documento redactado habitualmente en un período cercano a la muerte y por tanto garante de credibilidad en cuanto a las declaraciones de su redactor, dejaba explícita la cuantía de la deuda o parte de ella ${ }^{112}$.

Sobre la rentabilidad y contabilidad de estas sociedades apenas disponemos de fuentes archivísticas a diferencia de lo que sucedió en la zona de Cataluña, donde a lo largo de la Edad Moderna las compañías al quebrar ponían sus archivos a disposición judicial en el Fondo de Quiebras del Consulado de Comercio ${ }^{113}$. Al no haberse conservado libros de contabilidad - “de qüenta y raçón”, libros de caja y borradores- hemos de recurrir a referencias indirectas para determinar su nivel de ganancias. Los documentos fundacionales sólo se preocupan de especificar algunas partidas que debían detraerse de los beneficios a la hora de repartir las ganancias entre los socios, entre ellas los salarios de los mozos y el alquiler o compras de mulas donde se transportaba la mercancía ${ }^{114}$. En ocasiones también incluyen el alquiler de la vivienda o las reparaciones y mejoras efectuadas en ella ya que algunos asociados residían en la misma casa, aunque en habitáculos diferenciados. En la parte baja tenían situada la tienda o taller de trabajo ${ }^{115}$. Así mismo entraba en el monto de los gastos habituales los relativos al carbón para la calefacción, asimismo las velas para la iluminación e incluso las limosnas a los pobres, inherentes a algunas de estas sociedades.

Entre los escasos datos conservados está el de la establecida entre el licenciado Alonso de Reinoso, vecino de Trujillo, con los mercaderes Francisco y Alonso de Ledesma para comercializar paños. La documentación señala que el primero obtuvo una media de un 10 por ciento de beneficios anuales ${ }^{116}$. En la dedicada al mismo fin, formada por Francisca López, y su yerno Juan de Ocrato, éstos ascendieron a un 26,5

112 A.R.Ch.Va. Registro de Ejecutorias. Caja 1895, 42. 24-II-1600; Registro de Ejecutorias. Caja 314, 6. 24-XII-1516.

113 Estas mismas carencias se aprecian para otras zonas del interior, caso de Vitoria o de Toledo, tanto para esta centuria como para la siguiente. Ver ANGULO MORALES, A.: Del éxito en los negocios al fracaso del consulado: La formación de la burguesía mercantil de Vitoria (1670-1840), Vitoria, Universidad del País Vasco, 2000, p. 354; PÉREZ SARRIÓN, G.: "Compañías mercantiles rurales y urbanas de Cataluña en el interior peninsular durante el siglo XVIII”, en LOBO CABRERA, M. y SUÁREZ GRIMÓN, V. (Eds.): El comercio en el Antiguo Régimen. III Reunión Científica de la Asociación Española de Historia Moderna, Vol. II, Las Palmas de Gran Canaria, Universidad de las Palmas de Gran Canaria 1994, p. 235; MONTEMAYOR, J.: Toléde entre fortune et déclin (1530-1640), Limoges, PULIM, 1996, p. 235.

114 Si la bestia de carga pertenecía a uno de los socios se le abonaba una cantidad diaria cuando salía fuera de la ciudad. En la compañía de Inés Canillas se estableció en medio real diario. A.H.P.Sa. P.N. Leg. 2921. 5-VII-1527. Fols. 510-513; Leg. 5075. 12-VIII-1574. Fols. 804-805.

115 A.H.P.Sa. P.N. Leg. 2925. 5-IX-1533. Fols. 280-281; Leg. 3140. 17-X-1534. Fols. 219-220; Leg. 4614. 20-IX-1575. Fols. 1805-1808; Leg. 2921. 5-VII-1527. Fols. 510-513; Leg. 5075. 12-VIII1574. Fols. 804-805.

116 A.H.P.Sa. P.N. Leg. 2910. 24-XII-1514. Fols. 103-105. 
por ciento del capital invertido ${ }^{117}$. La de Pedro Pablos y Antón Bajo, vecinos de Villares, con Pedro Santos, dedicada a la compra venta de puercos adquiridos en Palencia, situó su ganancia, antes de descontar gastos, en torno a un 20 por ciento ${ }^{118}$. La rentabilidad de las compañías salmantinas estuvo, como se puede observar, en niveles similares a los de otras ciudades castellanas, caso de Burgos, donde se situó entre el 20 y el 25 por ciento ${ }^{119}$.

\section{Consideraciones finales}

A modo de epílogo podemos afirmar que la ciudad de Salamanca manifestó en el terreno comercial un claro contraste entre unas compañías de ámbito local, de reducido radio de acción y de capital limitado ${ }^{120}$, dedicadas al trato de ganado y a la comercialización de productos textiles y alimenticios, frente a otras con una mayor proyección geográfica vinculadas al mundo editorial. La presencia de miembros de las más relevantes dinastías de editores europeos, como los Junta o los Portonaris, que monopolizaban es tipo de negocio en Florencia, Lyon, Venecia o Monferrato, constituyó un claro síntoma de la importancia de la urbe tormesina en el circuito internacional del libro, tal y como ha subrayado Marta de la Mano ${ }^{121}$. Algunos autores destacan el papel de la ciudad como el centro de mayor desarrollo de la tipografía en España en el siglo XVI, alzándose como la primera productora de "impresos científicos" durante este periodo, entendiendo este concepto en el marco de las coordenadas espacio-temporales de la época, y, junto a Medina del Campo, actuó como una de las más relevantes sucursales de las casas matrices editoriales francesas e italianas ${ }^{122}$.

Al igual que sucedía para el caso de Zamora, y como ya indicábamos a lo largo de este artículo, se necesitará complementar el estudio de estas fuentes notariales con otras -obligaciones, poderes, testamentos, etc.- para dar una visión más real de la

117 A.H.P.Sa. P.N. Leg. 3139. 20-III-1534. S.f.

118 A.R.Ch.Va. Registro de Ejecutorias. Caja 1459, 20. 25-III-1582.

119 CAUNEDO DEL POTRO, B.: "Comercio y hombres....art. cit., p. 265.

120 Similares a las de la zona Toscana del siglo XV, establecidas con un capital limitado y duración corta. GRUBB, J.: Provincial familias of the Renaissance: private and public life in the Veneto, Baltimore, Johns Hopkins University Press, 1996, p.110.

121 MANO GONZÁLEZ, M. de la: Op. cit. pp. 23 y 45.

122 CUESTA GUTIÉRREZ, L.: La imprenta en Salamanca. Avance al estudio de la tipografía salmantina (1480-1944), Salamanca, Universidad de Salamanca, 1960, p. 22; PORTAL MONGE, $M^{a}$. Y. y SENA ESPINEL, $M^{a}$ P.: "Artistas y artesanos del libro en Salamanca en el siglo XVI a través de los libros parroquiales de bautismo", Memoria ecclesiae, IX, 1996, p. 225; RUIZ FIDALGO, L.: La imprenta en Salamanca (1501-1600), Madrid, Arcolibros, 1994, p. 8. 
situación del comercio en Salamanca y del radio de acción de los mercaderes ${ }^{123}$; los sistemas crediticios empleados o los productos comercializados de cara a establecer modas y tendencias ${ }^{124}$. H. Lapeyre, en su análisis de la documentación de la Contaduría Mayor de Cuentas de Simancas relacionada con las listas de aduanas para el pago de diezmos de la Mar, se sorprendía de la ausencia de mercaderes en ciudades como León, Zamora y Salamanca para 1559-1560 llegando a la conclusión de que no contaban más que con comerciantes que hacían compras en las ferias de Castilla ${ }^{125}$. La documentación notarial salmantina pone de relieve la necesidad de matizar tales conclusiones ante la presencia de compañías, especialmente las de los libreros, que tuvieron un radio de acción mucho más amplio que las citadas ferias. En este sentido podemos indicar que la urbe tormesina siguió las tenencias apuntadas por Hilario Casado Alonso quien habla de tres diferentes círculos de comercio -local, interregional e internacional- para Castilla durante los siglos XV y XVI'26. (Vid. Tabla 3)

123 Se puede completar además con la información proporcionada en la obra de Anastasio Rojo Vega sobre mercaderes salmantinos. ROJO VEGA, A.: Guía de mercaderes y mercaderías en las Ferias de Medina del Campo. Siglo XVI, Valladolid, Fundación del Museo de las Ferias, 2004.

124 Diferentes estudios, como los de Elena María García Guerra o David Carvajal, han subrayado el papel de las cartas de obligación como el instrumento crediticio más empleado en la negociación comercial de las ferias castellanas del siglo XVI. GARCÍA GUERRA, E. Ma.: "Crédito y comercio en las ferias de Medina del Campo en la primera mitad del siglo XVI", en GARCÍA GUERRA E. M ${ }^{\mathrm{a}}$. y DE LUCA, G.: Il mercato del credito in età Moderna. Reti e operatori finanziari nello spazio europeo, Milano, 2010, p. 40; CARVAJAL DE LA VEGA, D.: "Crédito y préstamo entre los mercaderes castellanos a fines de la Edad Media", en BONACHÍA HERNANDO, J.A. y CARVAJAL DE LA VEGA, D.: Los negocios del hombre. Comercio y rentas en Castilla. Siglos XV y XVI, Valladolid, Castilla Ediciones, 2012, p. 72.

125 LAPEYRE, H.: "El comercio exterior de Castilla a través de las aduanas de Felipe II", Estudios y Documentos, LXI, 1981, p. 97.

126 CASADO ALONSO, H.: "El comercio burgalés y la estructuración del espacio económico español a fines de la Edad Media", en Itinerarios medievales e identidad hispánica: XXVII Semana de Estudios Medievales. Navarra, Gobierno de Navarra, 2001, p. 346. 


\begin{tabular}{|c|c|c|c|c|c|c|c|c|c|c|c|c|c|c|}
\hline \multirow{9}{*}{ 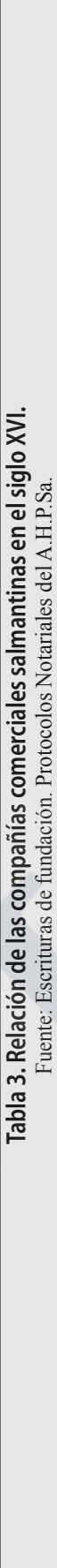 } & 离 $\frac{\bar{\Xi}}{\tilde{\Xi}}$ & $i \bar{n}$ in is & in 2 & 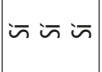 & $i \bar{\sim}=\frac{0}{2}$ & $\stackrel{2}{2}$ & 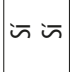 & 20 in & 2 in & 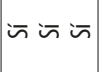 & शั & in 2 & in $\frac{0}{2}$ & 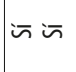 \\
\hline & 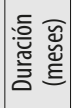 & 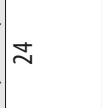 & \pm & \pm & $\sim$ & 旇 & 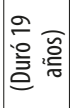 & 8 & กิ & जิ & $\simeq$ & $\approx$ & $\simeq$ & \pm \\
\hline & 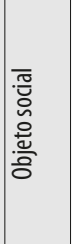 & 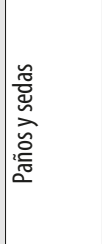 & 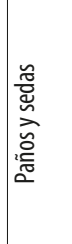 & 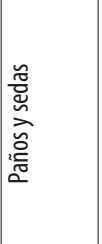 & 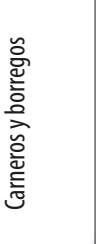 & 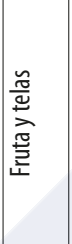 & 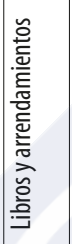 & 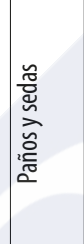 & जิ & 参 & 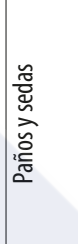 & 营 & 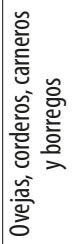 & 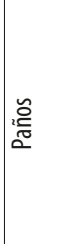 \\
\hline & 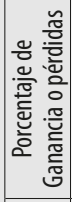 & जั & $\approx \approx$ & ஸें & 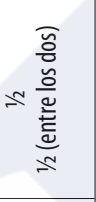 & 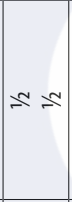 & & & $\approx \approx$ & & $\simeq^{2} \approx$ & $\approx \approx$ & $\approx \approx$ & 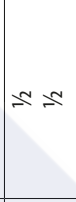 \\
\hline & 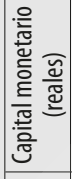 & ষ্ণ & $\stackrel{\infty}{\infty}$ & 壱 & 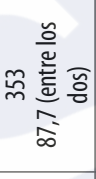 & 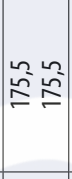 & जิ & 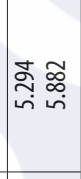 & $\bar{\sigma} \sigma$ & งิ งิ จิ & $\stackrel{\approx}{\approx}$ & जิ งิ & हิ & छু \\
\hline & 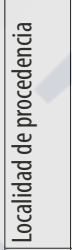 & 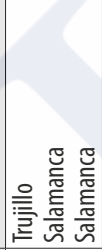 & 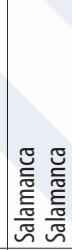 & 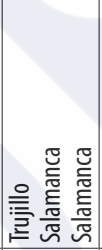 & 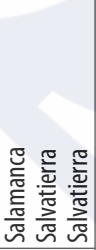 & 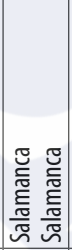 & 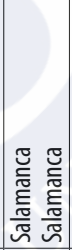 & 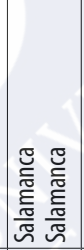 & 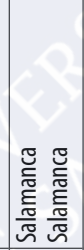 & 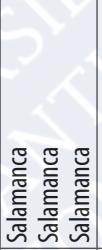 & 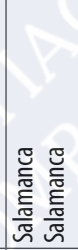 & 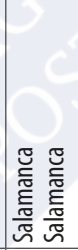 & 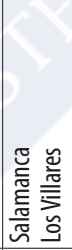 & 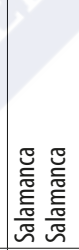 \\
\hline & :0 & 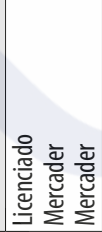 & $\frac{\bar{c}}{\bar{c}}$ & 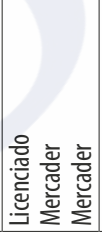 & & & 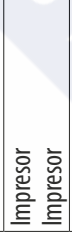 & 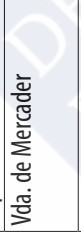 & 焉 & 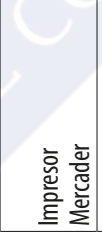 & 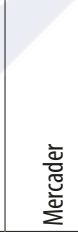 & 总 & 这 & 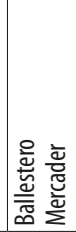 \\
\hline & 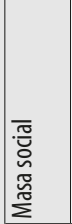 & 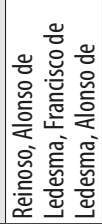 & 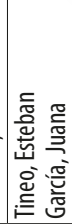 & 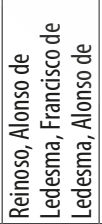 & 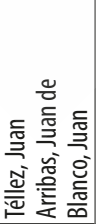 & 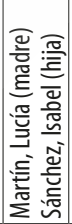 & 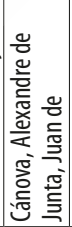 & 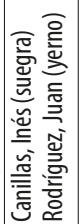 & 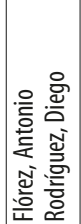 & 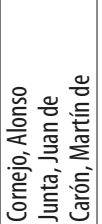 & 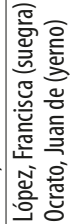 & 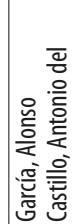 & 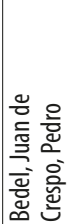 & 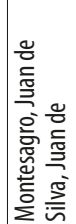 \\
\hline & 遈 & $\stackrel{\Delta}{i n}$ & $\stackrel{0}{i n}$ & in & $\frac{a}{n}$ & $\underset{\sim}{\sim}$ & $\tilde{\approx}$ & స్ & $\stackrel{\tilde{n}}{\cong}$ & 疍 & $\widetilde{\widetilde{n}}$ & $\cong$ & 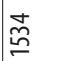 & 芯 \\
\hline
\end{tabular}




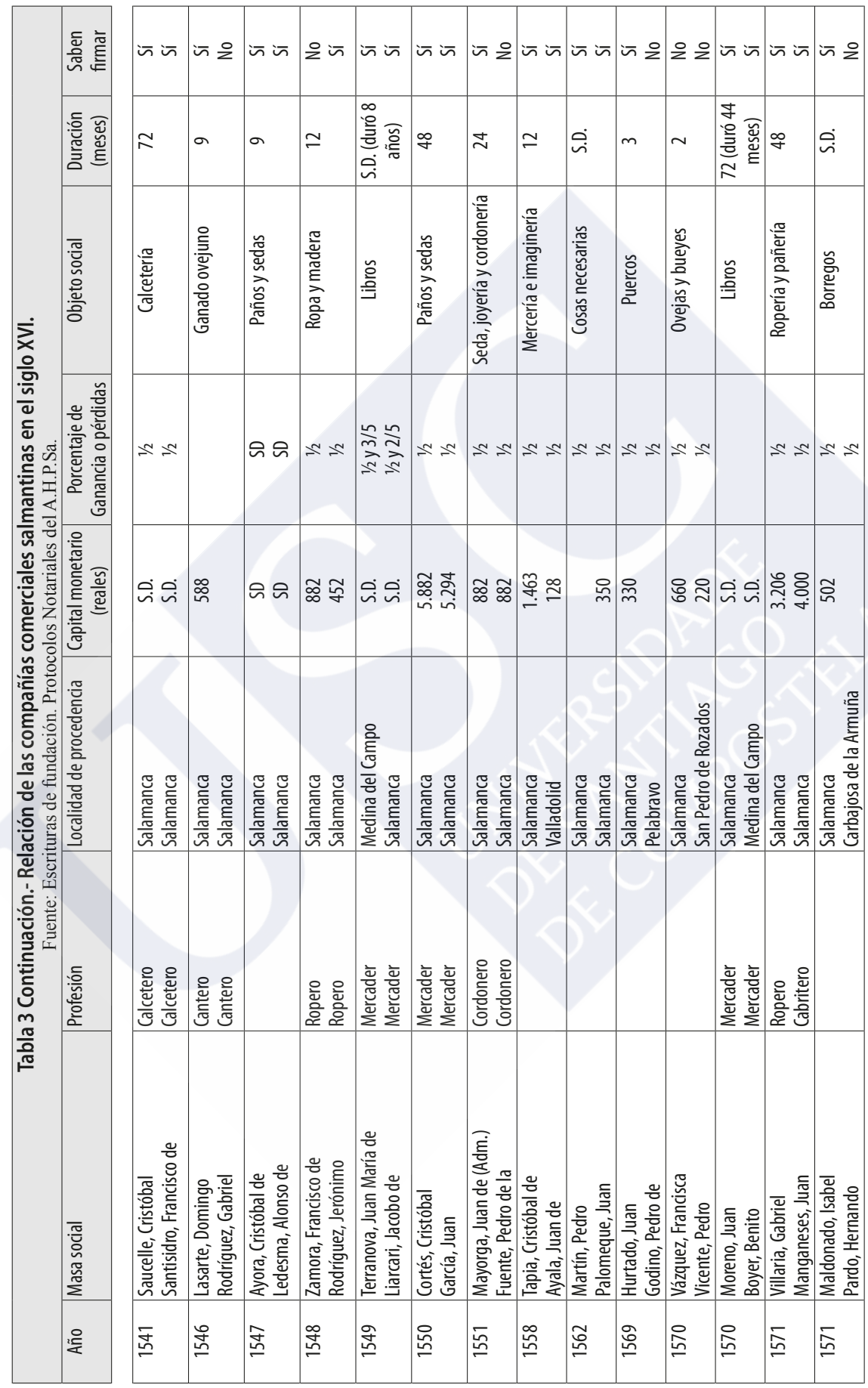


La formación de compañías

comerciales en Salamanca en el siglo XvI

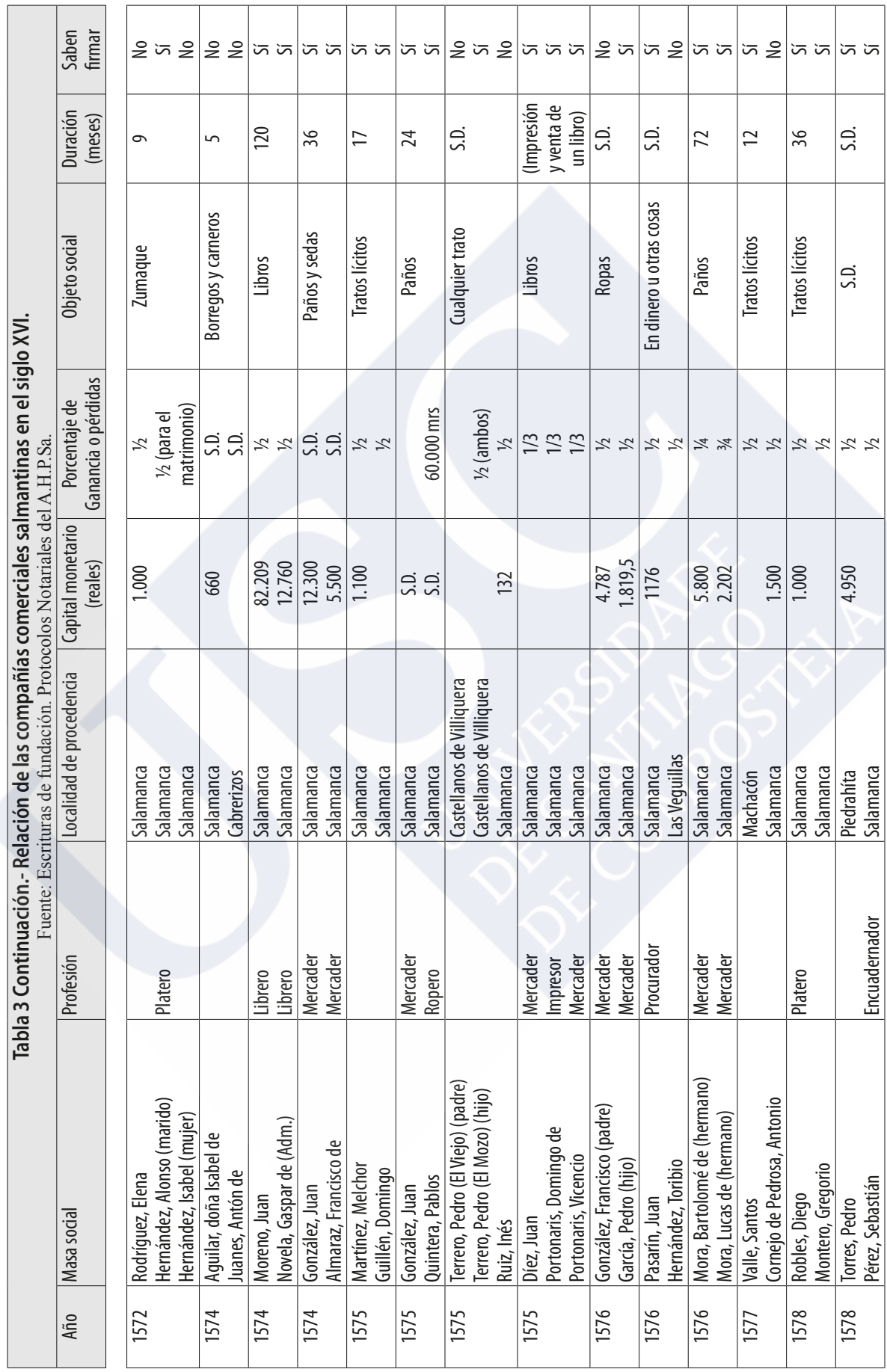




\begin{tabular}{|c|c|c|c|c|c|c|c|c|c|c|c|c|c|c|}
\hline \multirow{9}{*}{ 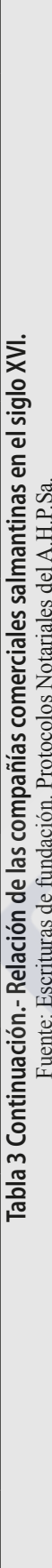 } & 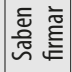 & 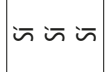 & 20 i & in $\approx$ 政 & 20 & 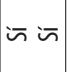 & 20 & in $\frac{0}{2}$ & 污沄 & 20 & in 2 & 202 & $2 \%$ & $2 \% 2$ \\
\hline & 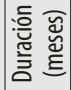 & $\approx$ & 0 & ถิ & $\simeq$ & ถิ & ถิ & \pm & ๓ి & $\sim$ & \pm & $\simeq$ & $\simeq$ & $\simeq$ \\
\hline & 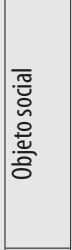 & 蒿 & 蒙 & 容 & 岕 & 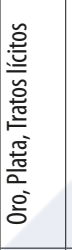 & 苞 & 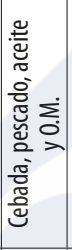 & 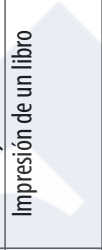 & 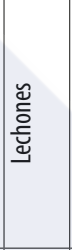 & 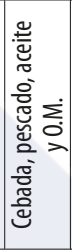 & 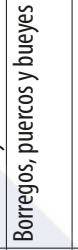 & 蒙 & 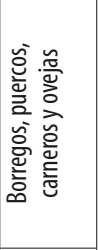 \\
\hline & 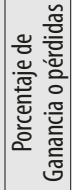 & & 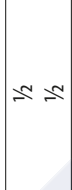 & 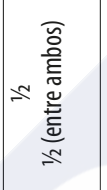 & $\approx \approx$ & $\approx \approx$ & & $\simeq \approx$ & $\stackrel{m}{=} \stackrel{m}{=}$ & $\therefore \approx$ & $x^{2} x^{2}$ & $\approx x^{2}$ & $x \approx$ & 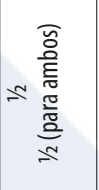 \\
\hline & 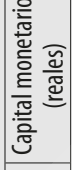 & जิ งิ जิ & जิ & $\stackrel{8}{\check{1}}$ & 危 & ठ্ & ָ̊ำ & ठ্ & $\approx$ & ผ & ঠి & f & 导 & 总 \\
\hline & 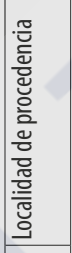 & 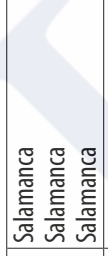 & 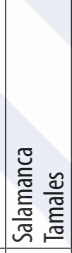 & 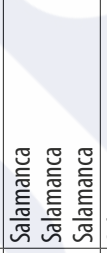 & 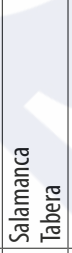 & 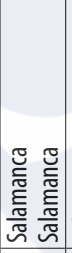 & 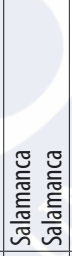 & 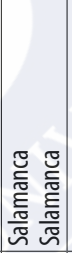 & 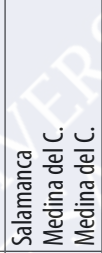 & 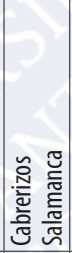 & 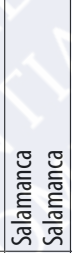 & 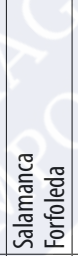 & 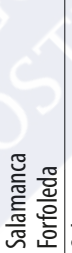 & 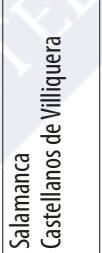 \\
\hline & 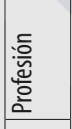 & 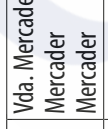 & & : & 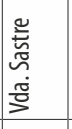 & $\begin{array}{l}\frac{9}{4} \\
\frac{\pi}{2} \\
\end{array}$ & & 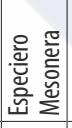 & 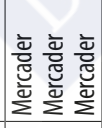 & 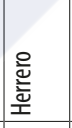 & 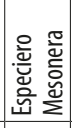 & 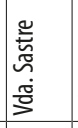 & 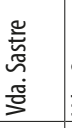 & 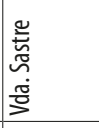 \\
\hline & 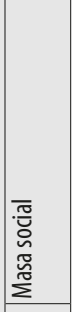 & 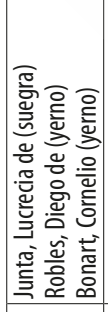 & 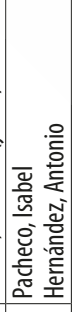 & 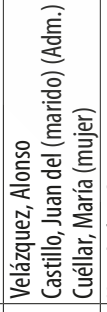 & 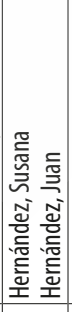 & 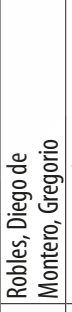 & 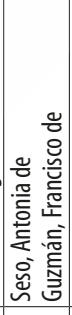 & 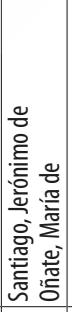 & 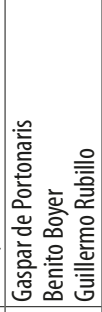 & 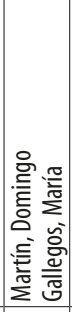 & 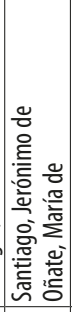 & 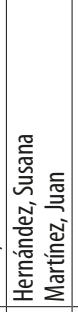 & 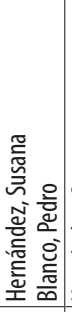 & 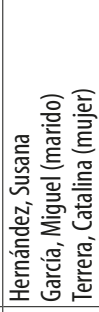 \\
\hline & 舜 & $\stackrel{\infty}{\infty}$ & 究 & $\stackrel{2}{n}$ & $\stackrel{2}{n}$ & i & 㫣 & 兽 & $\stackrel{\infty}{\infty}$ & $\stackrel{\infty}{\sim}$ & 总 & 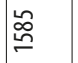 & 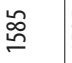 & 望 \\
\hline
\end{tabular}


La formación de compañías

comerciales en Salamanca en el siglo XvI

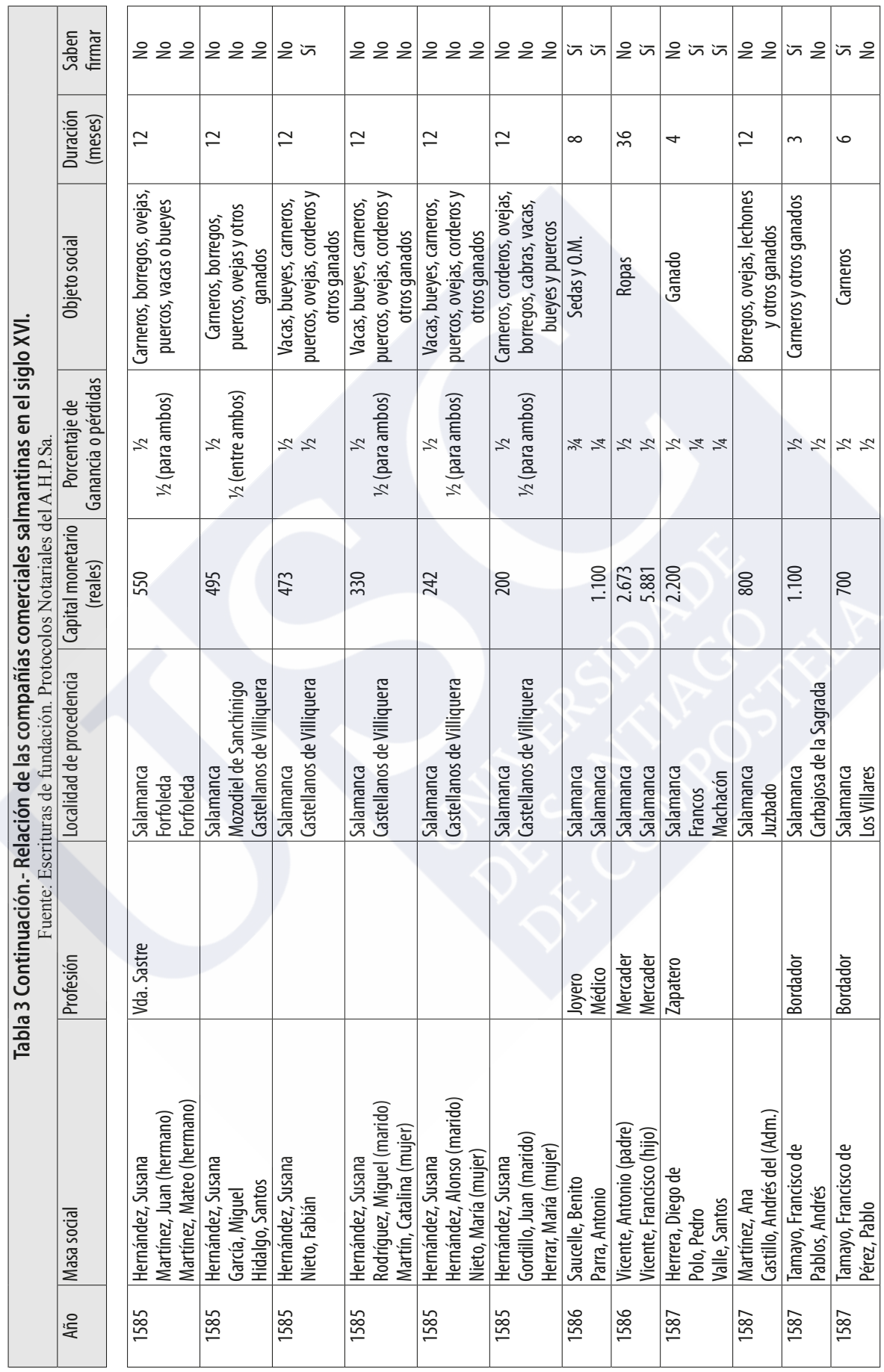




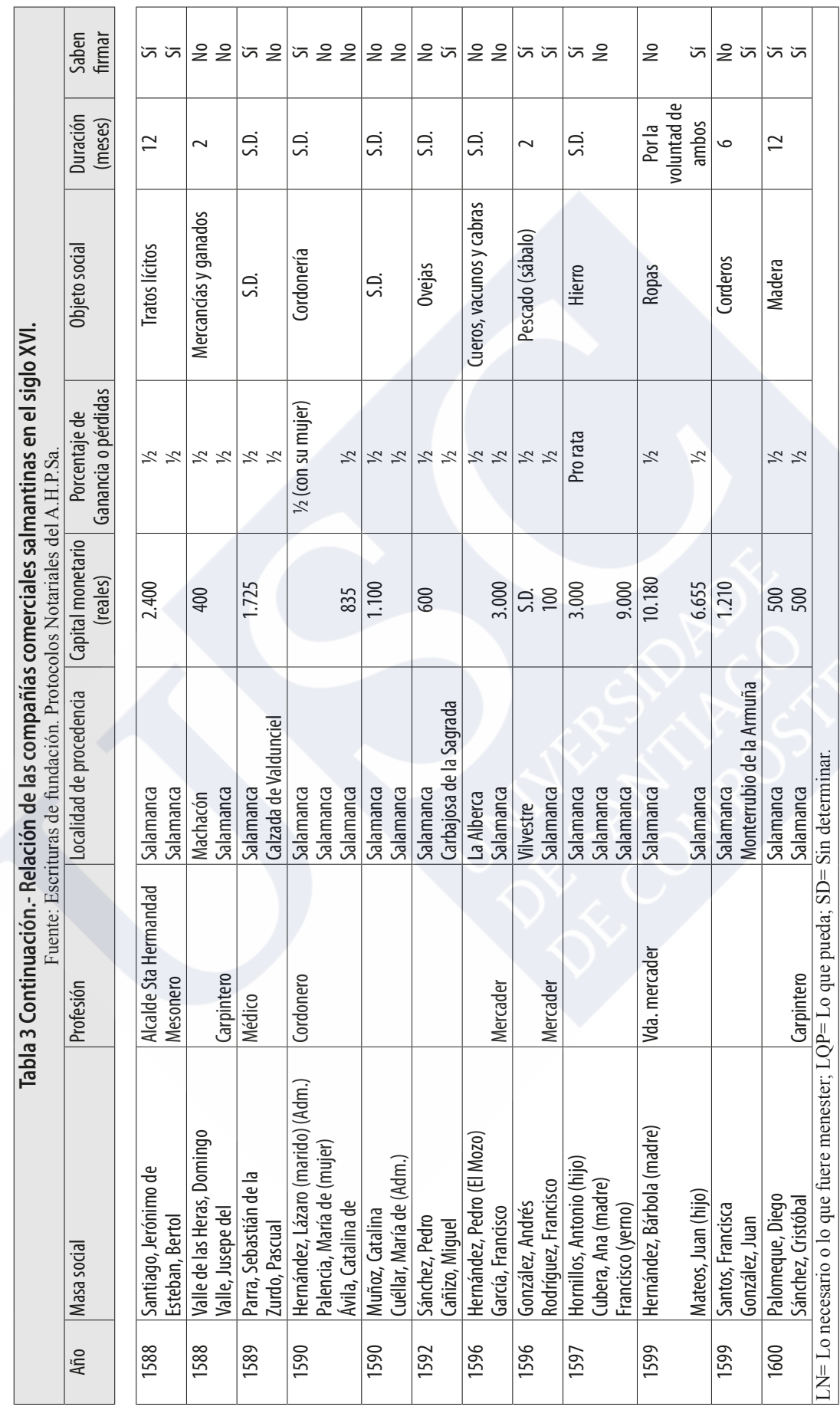

